Briaud, Jean-Louis

\title{
Case Histories in Soil and Rock Erosion: Woodrow Wilson Bridge, Brazos River Meander, Normandy Cliffs, and New Orleans Levees
}

Verfügbar unter / Available at:

https://hdl.handle.net/20.500.11970/100094

Vorgeschlagene Zitierweise / Suggested citation:

Briaud, Jean-Louis (2008): Case Histories in Soil and Rock Erosion: Woodrow Wilson Bridge, Brazos River Meander, Normandy Cliffs, and New Orleans Levees. In: Sekiguchi, Hideo (Hg.): Proceedings 4th International Conference on Scour and Erosion (ICSE-4). November 5-7, 2008, Tokyo, Japan. Tokyo: The Japanese Geotechnical Society. S. 1-27. 


\title{
CASE HISTORIES IN SOIL AND ROCK EROSION: Woodrow Wilson Bridge, Brazos River Meander, Normandy Cliffs, and New Orleans Levees
}

\author{
JEAN-LOUIS BRIAUD \\ Zachry Dept. of Civil Eng., Texas A\&M University \\ 3136 TAMUS, College Station Texas 77843-3136, USA \\ Tel: (979) 845-3795 \\ E-mail:briaud@tamu.edu
}

\section{Reprinted with permission from ASCE \\ ASCE Reference:}

BRIAUD J.-L., 2008, "Case Histories in Soil and Rock Erosion: Woodrow Wilson Bridge, Brazos River Meander, Normandy Cliffs, and New Orleans Levees", The 9th Ralph B. Peck Lecture, Journal of Geotechnical and Geoenvironmental Engineering, Vol 134 No. 10, ASCE, Reston, Virginia, USA.

\begin{abstract}
This lecture presents four case history examples of erosion processes. Because the topic of soil and rock erosion is relatively underdeveloped in geotechnical engineering, an introduction precedes the case histories to describe some fundamental aspects of erosion. Erosion involves the soil or rock through its erodibility, the water through its velocity, and the geometry of the obstacle through its size and shape. Knowledge of these three components is needed for any erosion problem to be studied and solved. A set of fundamental issues are addressed in a first part including an erodibility classification for soils and rocks, an explanation of the stresses imposed by the water on the soil-water or rock-water interface, and an explanation of how the geometry impacts the problem. The Woodrow Wilson Bridge case history outlines a new and less conservative method to compute the scour depth and gives examples of bridge scour calculations. The Brazos River meander case history outlines a new method to predict meander migration and gives an example of migration calculations. The Pointe du Hoc case history gives an explanation of a process of rock cliff erosion. The New Orleans levees case history gives an example of erosion of levees by overtopping and proposes an erosion design chart for levee overtopping. Whenever possible the results are presented in a probabilistic fashion. All case histories make use of the EFA, an apparatus developed to quantify the erodibility of a soil or rock and to give the constitutive law for erosion problems: the erosion function. The power point slides for the lecture including many photos of the case histories are available at http://ceprofs.tamu.edu/briaud/ under "Lectures" and the video (DVD) of the lecture is available from the author, free of charge.
\end{abstract}

Key Words : erosion, scour, laboratory testing, field measurements, soil, rock, case histories, bridges, meander, migration, cliffs, levees, overtopping

\section{SPECIAL THANKS TO PROFESSOR PECK}

I would like to thank Professor Peck for his very positive influence on my career, starting in 1972 when I arrived in North America, not speaking
English, purchasing a copy of "Terzaghi and Peck" as well as an English-French dictionary, and translating the book at a rate of 2 hours per page. In 1975, after discovering that I would really enjoy an academic career, I decided to obtain a $\mathrm{PhD}$ and wrote to several prominent geotechnical engineers world 
wide including Ralph Peck to seek advice on what research topic to work on and which university to go to. Professor Peck took the time to answer my query in a wonderful letter and his advice was very precious. In 1993, Ralph Peck agreed to be the first Buchanan Lecturer and that was critical in setting the tone for the future of this now well known annual lecture at Texas A\&M University. In 1998, as I was approached by some universities for an administrative career, I again asked Ralph's advice who told me that if I enjoyed the students, the technical activities, and the discovery process I should stay away from administration. I followed that advice and am very happy to have done so. This Peck Lecture is another one of Professor Peck's very positive impact on my career.

\section{INTRODUCTION}

This lecture starts with an introduction to some fundamental aspects of erosion based on the author's work and then goes on to show how these fundamentals are used in the prediction of erosion processes for four case histories. The first case history is the Woodrow Wilson Bridge on the Potomac River in Washington D.C.; it is related to bridge scour predictions. The second case history is the Brazos River at State Highway 105 near Texas A\&M University; it is related to meander migration. The third case history is the Cliffs of Pointe du Hoc in Normandie, France, one of World War II D-Day invasion sites on June 6th, 1944; it is related to rock cliffs erosion by wave action. The fourth case history is the New Orleans levees during Hurricane Katrina; it is related to levee overtopping erosion. The power point slides for the lecture including many photos of the case histories are available at http://ceprofs.tamu.edu.briaud/ under "Lectures" and the video (DVD) of the lecture is available from the author free of charge.

\section{FUNDAMENTALS OF EROSION}

Several geotechnical engineers and researchers have contributed to the advancement of the field of erosion. Among many others, one notes the work of Sherard on internal erosion of dams (e.g.: Sherard, 1985), Chapuis on the rotating cylinder to measure the erosion properties of stiff soils (e.g.: Chapuis, Gatien, 1986), Arulanandan on the use of electrical resistivity to predict soil erodibility (e.g.: Arulanandan et al., 1973), Hanson on the jet test to measure the erosion properties of soils (e.g.: Hanson, 1991), and Fell on the hole erosion test to measure the erosion properties of soils (e.g.: Wan, Fell, 2004). The following is a summary based mainly on the author's work over the last 18 years.

The input to an erosion problem is always three fold: the soil or rock, the water, and the geometry of the obstacle that the water is encountering. The soil or rock is characterized mainly by its erodibility, the water mainly by its velocity and the geometry of the obstacle by its dimensions. Each one of these components is discussed next.

\section{(1) Soil erodibility}

Soil is defined here as an earth element which can be classified by the Unified Soil Classification System (USCS). This classification makes a distinction between coarse grained soils and fine grained soils and identifies clay size, silt size, sand size, and gravel size particles. It is common practice in the world of erosion to refer to fine grained soils as cohesive soils and to coarse grained soils as cohesionless soils. This practice is not appropriate as many fine grained soils have no effective stress cohesion intercept. Rock is defined here as an earth element which has a joint spacing of more than $0.1 \mathrm{~m}$ and an unconfined compressive strength of the intact rock core (rock substance) of more than $500 \mathrm{kPa}$. Intermediate between soils and rocks are intermediate geomaterials such as cobbles, boulders, and rip-rap.

Fig. 1 shows a free body diagram sketch which can represent a soil particle, a cluster of particles, or a rock block at the bottom of a lake. The water imposes a normal stress (hydrostatic pressure) around the soil particle or rock block. The normal stress is slightly higher at the bottom than at the top since the bottom is slightly deeper in the water column. This normal stress difference creates the buoyancy force which

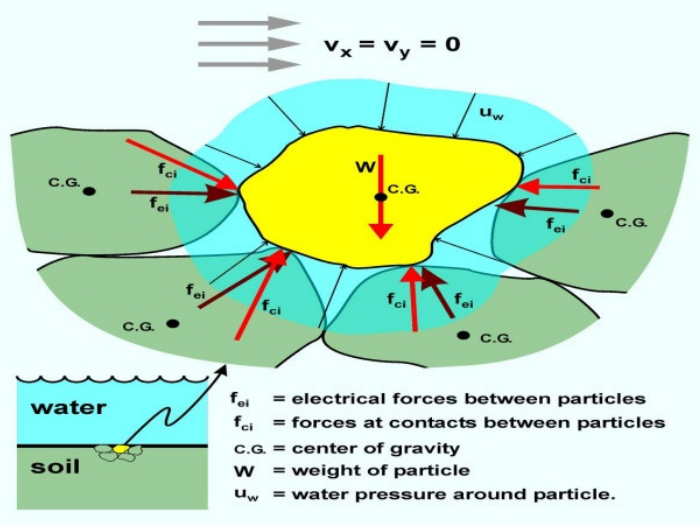

Fig.1 Free body diagram of a soil particle or rock block for a no flow condition 


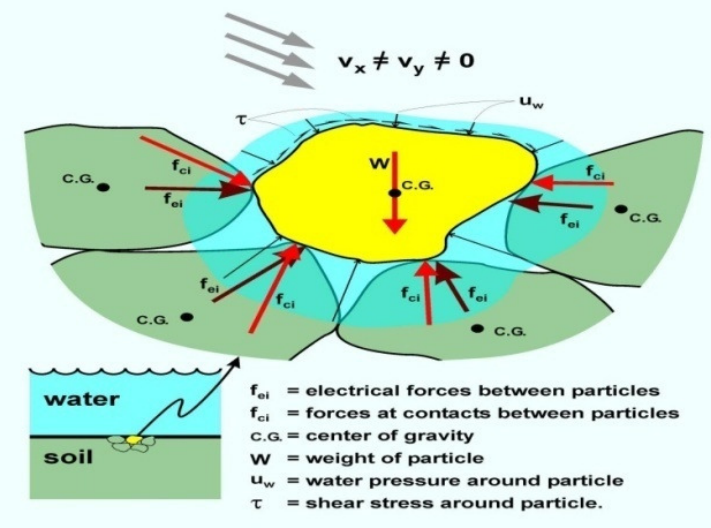

Fig.2 Free body diagram of a soil particle or rock block when the water flows

reduces the weight of the soil particle or rock block. Fig. 2 shows a soil particle, a cluster of particles, or a rock block at the bottom of a flowing river. Three things happen when the water starts flowing. First, a drag force and associated shear stresses develop at the interface between the soil particle or rock block and the water flowing over it. Second, the normal stress on top of the soil particle or rock block decreases because of the water flow. Indeed, as the velocity increases around the particle or the obstacle, the pressure drops to maintain conservation of energy according to Bernoulli's principle. This phenomenon is similar to the air flow on top of an airplane wing where the pressure is lower than below the wing thereby developing the uplift force necessary for the plane to fly. Third the normal stresses and shear stresses applied at the boundaries are fluctuating with time because of the turbulence in the water. These fluctuations find their roots in the appearance and disappearance of eddies, vortices, ejections, and sweeps in the flowing water; they can contribute significantly to the erosion process especially at higher velocities. In some cases they are the main reason for erosion. The contribution of turbulence fluctuations to the erosion process has been studied by several authors including Croad (1981), Raudkivi (1998), Hoffmans and Verheij (1997), Bollaert (2002), Hofland et al. (2005). The combination of the mean value and the fluctuations around the mean of the drag force and uplift force can become large enough to pluck and drag the soil particle, soil particle cluster, or rock block away and generate erosion.

Note that in the case where the soil particle is subjected to suction (tensile stress in the inter-particle water), the mechanical inter-particle compressive forces ( $f_{\mathrm{ci}}$ in Figure 1 and 2 ) can be significantly larger than in the case where the water is in compression. This apparent cohesion may

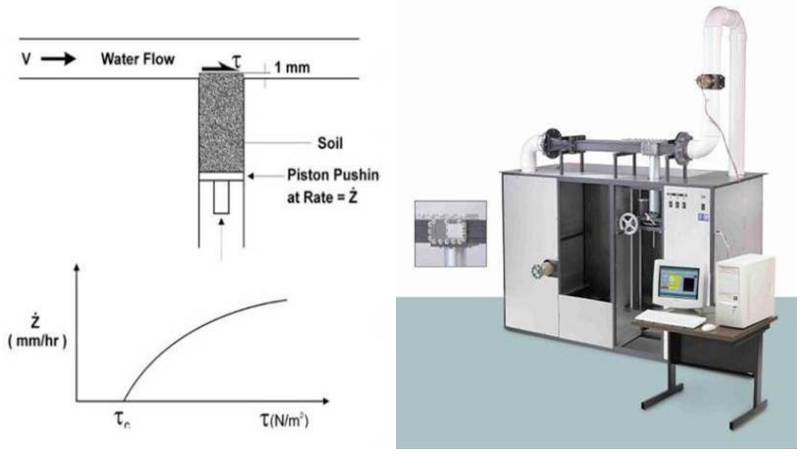

Fig.3 Erosion Function Apparatus to measure erodibility (Briaud et al., 1999)

increase the resistance to erosion at least until the flow and presence of water destroys the suction.

Erodibility of a soil or rock can be defined as the relationship between the erosion rate $\dot{Z}$ and the velocity of the water $v$ near the soil-water interface. This definition is not very satisfactory because the velocity varies in direction and intensity in the flow field. In fact, strictly speaking, the water velocity is zero at the soil/rock-water interface. A more satisfactory definition is the relationship between the erosion rate $\dot{Z}$ and the shear stress $\tau$ at the soil/rock-water interface.

$$
\dot{Z}=f(\tau)
$$

The erosion function described by Eq. 1 represents the constitutive law of the soil or rock for erosion problems much like a stress strain curve would represent the constitutive law of the soil or rock for a settlement problem. While a shear stress based definition is an improved definition over a velocity based definition, it is still not completely satisfactory as the shear stress is not the only stress which contributes to the erosion rate. A more complete description of the erosion function is given by Eq. 2:

$$
\frac{\dot{Z}}{u}=\alpha\left(\frac{\tau-\tau_{c}}{\rho u^{2}}\right)^{m}+\beta\left(\frac{\Delta \tau}{\rho u^{2}}\right)^{n}+\delta\left(\frac{\Delta \sigma}{\rho u^{2}}\right)^{p}
$$

Where $\dot{Z}$ is the erosion rate $(\mathrm{m} / \mathrm{s})$, $u$ the water velocity $(\mathrm{m} / \mathrm{s}), \tau$ the hydraulic shear stress, $\tau_{c}$ the threshold or critical shear stress below which no erosion occurs, $\rho$ the mass density of water $\left(\mathrm{kg} / \mathrm{m}^{3}\right)$, $\Delta \tau$ the turbulent fluctuation of the hydraulic shear stress, and $\Delta \sigma$ the turbulent fluctuation of the net uplift normal stress. All other quantities are parameters characterizing the soil being eroded. While this model is quite thorough, it is rather 

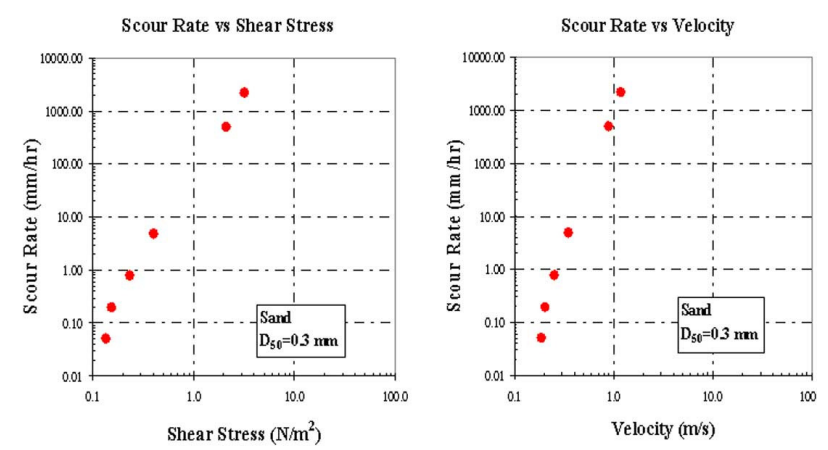

Fig.4 Erosion function for a fine sand as measured in the EFA
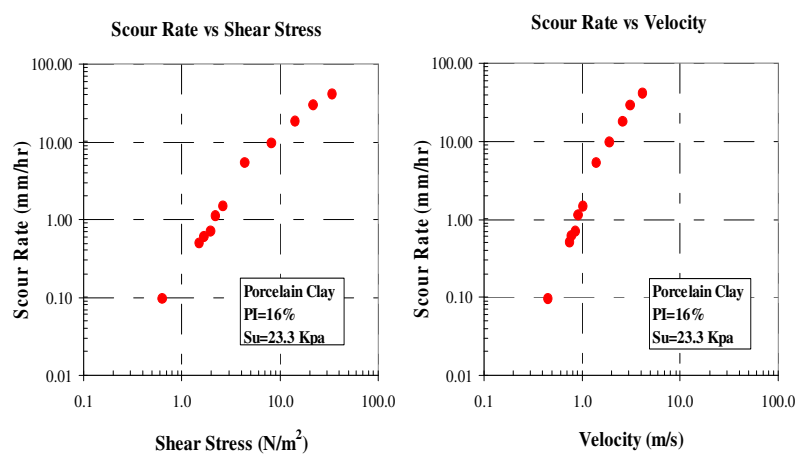

Fig.5 Erosion function for a low plasticity clay as measured in the EFA

impractical at this time to determine the 6 parameters needed in Eq. 2 on a site specific and routine basis. Today Eq. 1 is widely accepted and will be the definition used in this lecture; it corresponds to the first term in Eq. 2:

$$
\frac{\dot{Z}}{u}=\alpha\left(\frac{\tau-\tau_{c}}{\rho u^{2}}\right)^{m}
$$

As additional fundamental work is performed in erosion engineering, it is likely that Eq. 3 will evolve towards Eq. 2.

An apparatus was developed in the early 1990s to measure the erosion function. It is called the Erosion Function Apparatus or EFA (Fig. 3, Briaud et al., 2001a). The principle is to go to the site where erosion is being investigated, collect samples within the depth of concern, bring them back to the laboratory and test them in the EFA. The $75 \mathrm{~mm}$ outside diameter sampling tube is placed through the bottom of the conduit where water flows at a constant velocity (Fig. 3). The soil or rock is pushed out of the sampling tube only as fast as it is eroded by the water flowing over it. For each velocity, an erosion rate is measured and a shear stress is calculated using Moody's chart (Moody, 1944). Point by point the erosion function is obtained.

For fine grained and coarse grained soils, ASTM standard thin wall steel tube samples are favored. If such samples cannot be obtained (e.g.: coarse grained soils), Split Spoon SPT samples are obtained and the coarse grained soil is reconstituted in the thin wall steel tube. Fortunately in the case of erosion of coarse grained soils, soil disturbance does not affect the results significantly. If it is representative of the rock erosion process to test a $75 \mathrm{~mm}$ diameter rock sample, the rock core is placed in the thin wall steel tube and tested in the EFA. Example erosion functions are shown in Fig. 4 for a fine sand and Fig. 5 for low plasticity clay. Note that for the same average velocity of $1 \mathrm{~m} / \mathrm{s}$ in the EFA test conduit, the rate of erosion for the sand is about 1000 times faster than for the clay. This indicates that the rate of erosion can be very different for different soils.

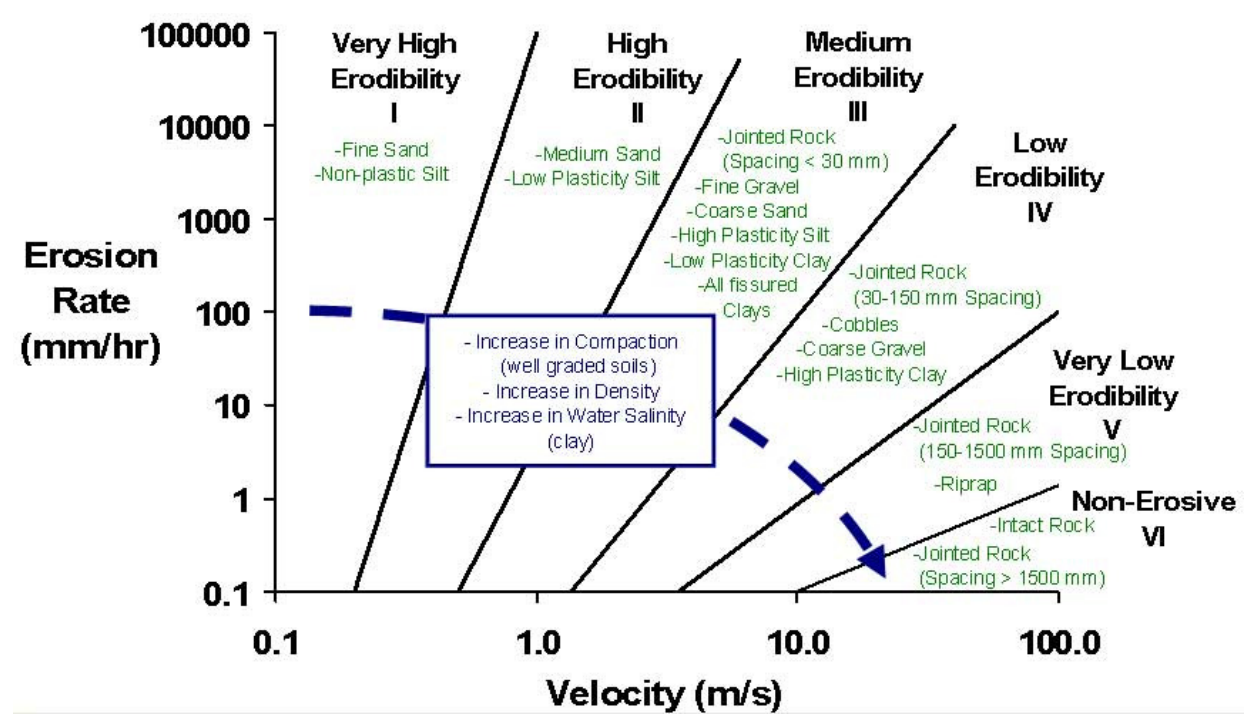

Fig.6 Proposed erosion categories for soils and rocks based on velocity 


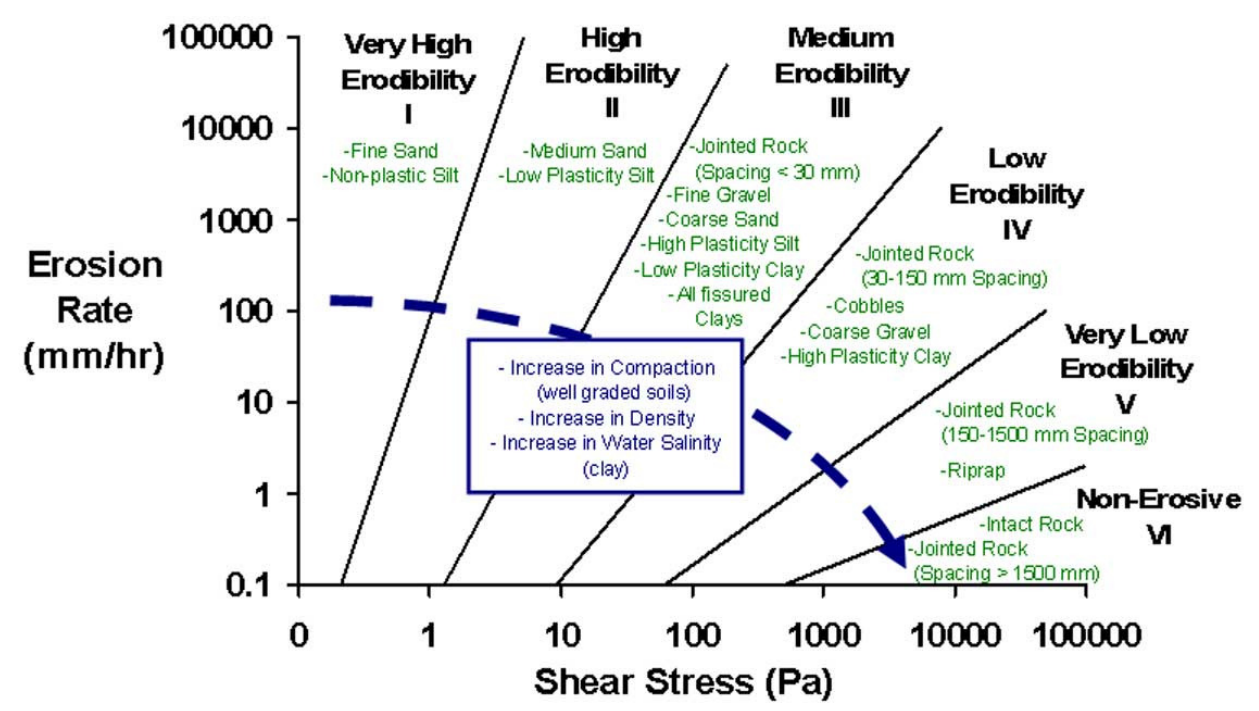

Fig.7 Proposed erosion categories for soils and rocks based on shear stress

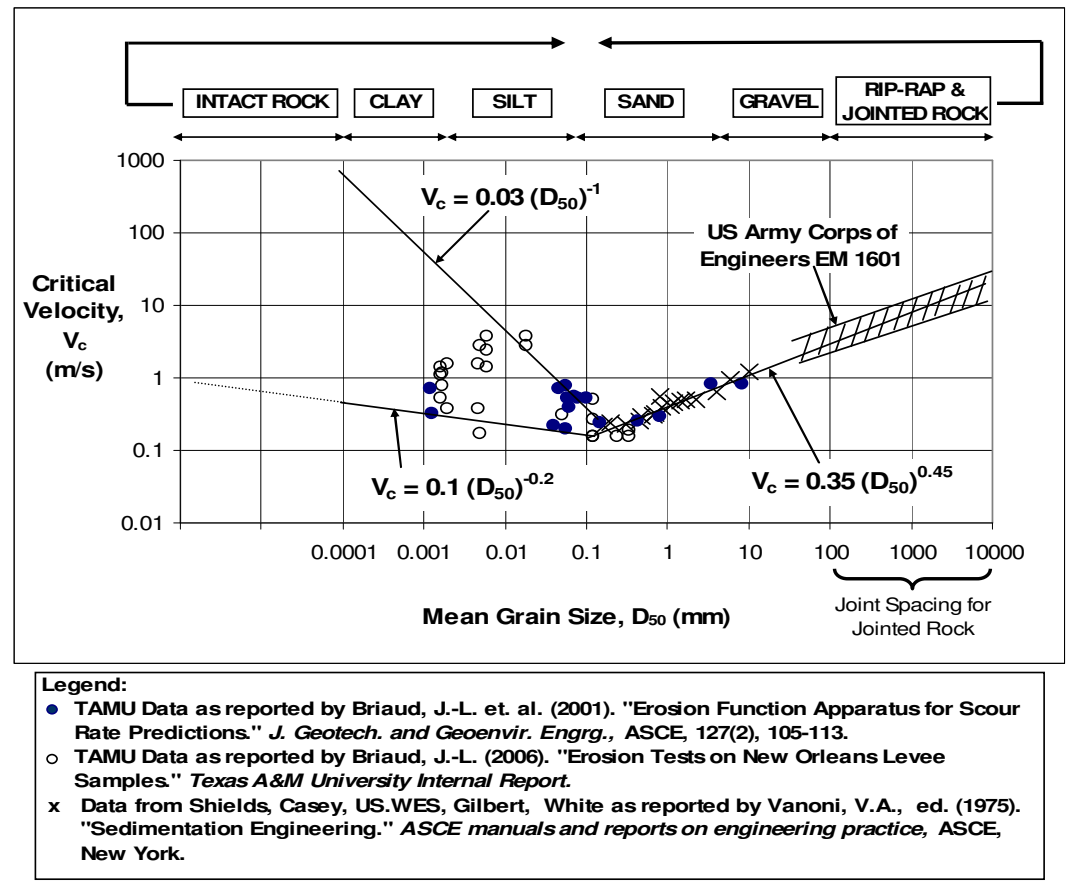

Fig.8 Critical velocity as a function of mean grain size

Other devices have been developed to evaluate how resistant earth materials are to water flow. These include the rotating cylinder to measure the erosion properties of stiff soils (e.g.: Chapuis, Gatien, 1986), the jet test to evaluate the erodibility of soils (e.g.: Hanson, 1991), and the hole erosion test to measure the erosion properties of stiff soils (e.g.: Wan, Fell, 2004).

Categories are used in many fields of engineering: soil classification categories, hurricane strength categories, earthquake magnitude categories. Such categories have the advantage of quoting one number to represent a more complex condition. Erosion categories are proposed (Fig. 6) in order to bring erodibility down in complexity from an erosion rate vs shear stress function to a category number. Such a classification system can be presented in terms of velocity (Fig. 6) or shear stress (Fig. 7). The categories proposed are based on 15 years of erosion testing experience. In order to classify a soil or rock, the erosion function is plotted on the category chart and the erodibility category number for the material tested is the number for the zone in which the erosion function fits. Note that, as discussed later, using the water velocity is less representative and leads to more uncertainties than using the shear stress; indeed the velocity and the shear stress are not linked by a constant. Nevertheless the velocity chart is presented 


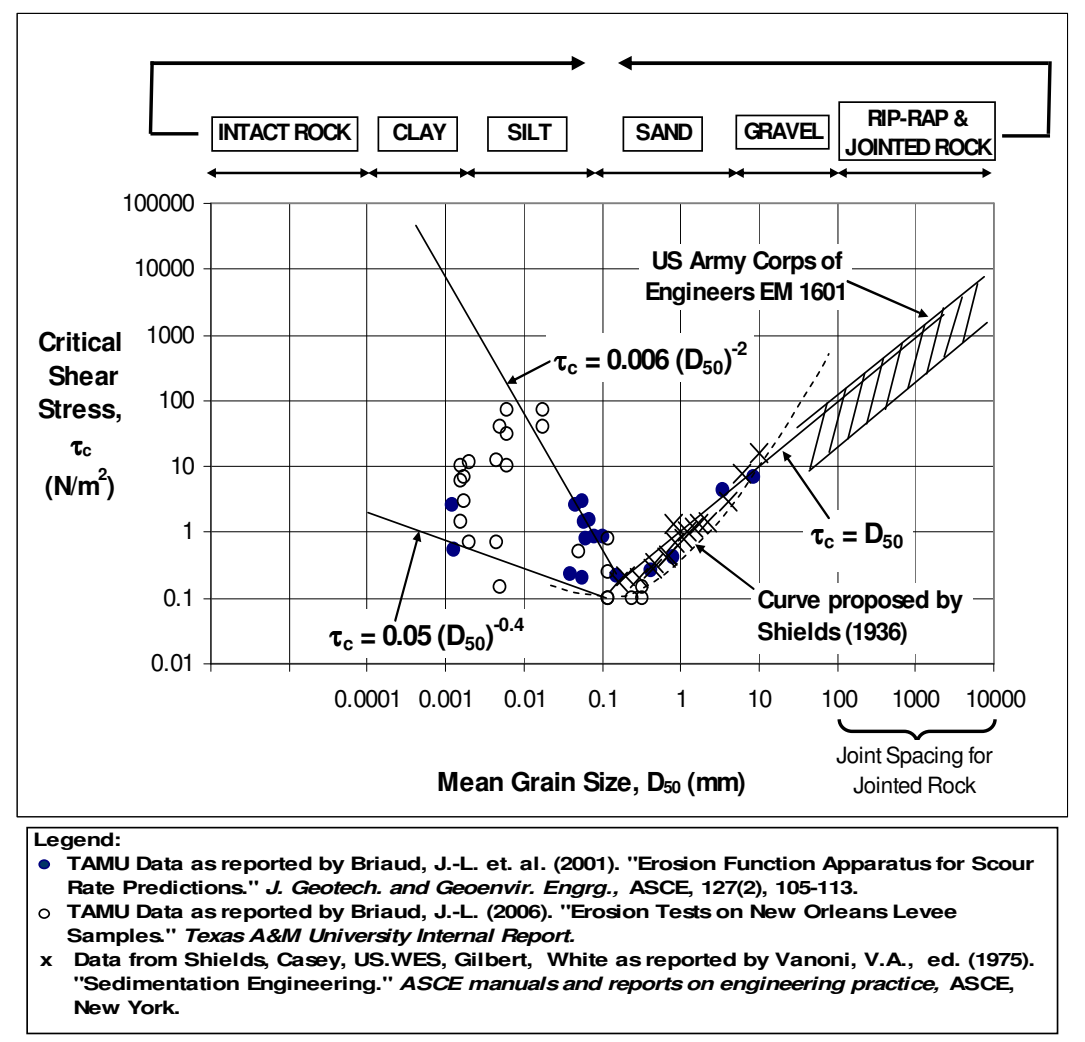

Fig.9 Critical shear stress as a function of mean grain size

Table 1 Soil properties influencing erodibility

Soil water content

Soil unit weight

Soil plasticity index

Soil undrained shear str.

Soil void ratio

Soil swell

Soil mean grain size

Soil percent passing \#200

Soil clay minerals

because it is easier to gage a problem in terms of velocity.

One of the most important soil parameters in erosion studies is the threshold of erosion. Below this threshold, erosion does not occur and above this threshold, erosion occurs. In terms of shear stress, this threshold is the critical shear stress $\tau_{c}$ and in terms of velocity, it is the critical velocity $v_{c}$. Fig. 8 shows a plot of the critical velocity as a function of the mean grain size while Fig. 9 shows the same plot for the critical shear stress. The data come from measurements in the EFA as well as measurements published in the literature. As can be seen on Fig. 8 and 9, the relationship between the critical value and the grain size has a $\mathrm{V}$ shape indicating that the most erodible soils are fine sands with a mean grain size in the range of 0.1 to $0.5 \mathrm{~mm}$. This $\mathrm{V}$ shape also points out that particle size controls the erosion threshold of coarse grained soils while particle size does not correlate with the erosion threshold of fine grained soils. Note that Shields (1936) proposed a curve for coarse grain soils in his doctoral work; his data is included in Fig. 8 and 9. Shields recommendations do not include fine grain soils. Note also that Hjulstrom (1935) proposed such a curve for both coarse grain soils and fine grain soils but his recommendations for fine grain soils turned out to be too simple.

The erodibility of soils varies significantly from one soil to the next; therefore erodibility depends on the soil properties. It depends also on the properties of the water flowing over the soil. For some soils, particularly dispersive soils, the higher the salt concentration in the water, the more erosion resistant a clay is (Cao et al., 2002, Croad, 1981). The properties influencing erodibility are numerous; some of them are listed in Table 1. It appears reasonable to expect that a relationship would exist between common soil properties and erodibility. But erodibility is a function not a number therefore correlations can only be made with elements of that function such as the critical shear stress or the initial slope of the erosion function. Such correlations have been attempted (Cao et al., 2002) and failed (Fig. 10). On one hand, there should be a correlation, on 


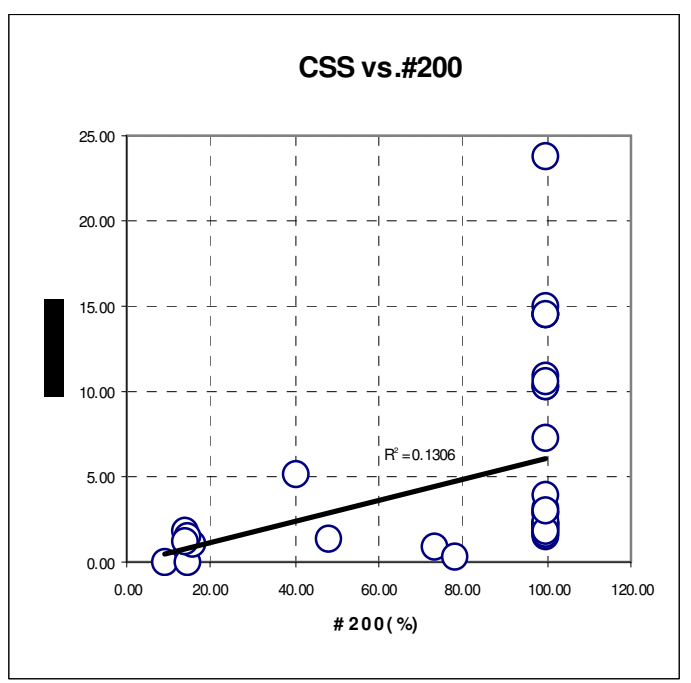

(a)

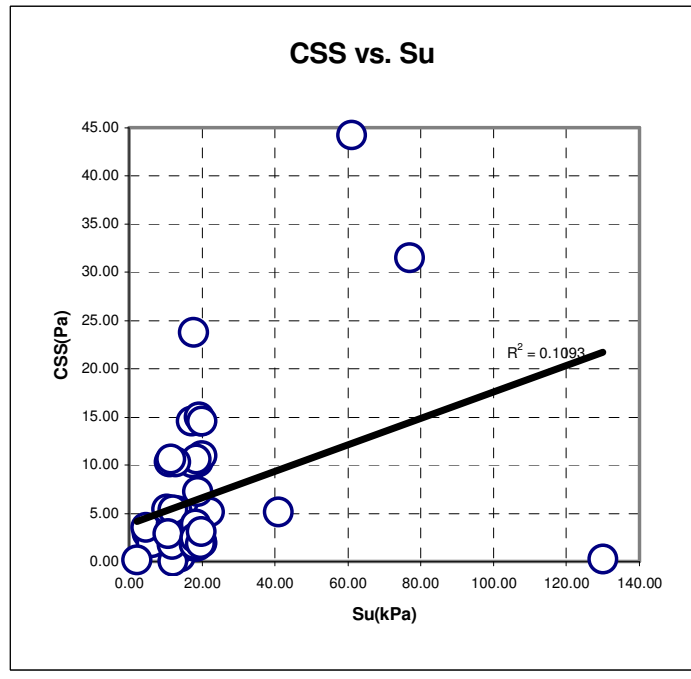

(b)

Fig.10 Failed attempts at correlation s between the critical shear stress and the percent passing sieve \#200 (a), and the undrained shear strength (b)

the other hand, the correlation is complex and requires multiple parameters all involved in the resistance of the soil to erosion. All in all it is preferable to measure the erosion function directly in an apparatus such as the EFA.

\section{(2) Rock erodibility}

If soil erosion is not very well known, rock erosion is even less known and the engineer must exercise a great deal of engineering judgment when it comes to rock erosion. Nevertheless many engineers and researchers have contributed to the advancement of knowledge in this relatively new field. They include Temple and Moore (1994), Annandale (1995), Kirsten et al. (1996), van Schalkwyk et al. (1995), Bollaert (2002), Manso (2006).

Rock erodes through two main processes: rock substance erosion and rock mass erosion. Rock substance erosion refers to the erosion of the rock material itself while rock mass erosion refers to the removal of rock blocks from the jointed rock mass. Rock substance erosion includes three sub-mechanisms: erosion due to the hydraulic shear stress created by the water at the rock-water interface, erosion due to abrasion caused by sediments rubbing against the rock during the flow, and impact of air bubbles that pit the rock surface due to cavitation at very high velocities. Rock mass erosion includes two sub mechanisms: erosion due to slaking, and erosion due to block removal between joints. Slaking can occur when a rock, such as a high plasticity shale in an ephemeral stream, dries out and cracks during summer months; these small blocks are then removed by the next big flood. Block removal can occur if, during high turbulence events, the
Table 2 Rock mass erosion; this table is preliminary in nature and should be calibrated against field behavior

\begin{tabular}{|c|c|c|c|}
\hline $\begin{array}{c}\text { Joint } \\
\text { Spacing } \\
(\mathrm{mm})\end{array}$ & $\begin{array}{c}\text { Critical } \\
\text { Velocity } \\
(\mathrm{m} / \mathrm{s})\end{array}$ & $\begin{array}{l}\text { Erosion } \\
\text { Category }\end{array}$ & $\begin{array}{l}\text { Orientation } \\
\text { of joints }\end{array}$ \\
\hline$<30$ & $0.5-1.35$ & $\begin{array}{c}\text { Category III } \\
\text { Medium }\end{array}$ & Not applicable \\
\hline $30-150$ & $1.35-3.5$ & $\begin{array}{c}\text { Category IV } \\
\text { Low }\end{array}$ & $\begin{array}{c}\text { Evaluation } \\
\text { needed }\end{array}$ \\
\hline $\begin{array}{l}150- \\
1500 \\
\end{array}$ & $3.5-10$ & $\begin{array}{c}\text { Category V } \\
\text { Very Low }\end{array}$ & $\begin{array}{c}\text { Evaluation } \\
\text { needed }\end{array}$ \\
\hline$>1500$ & $>10$ & $\begin{array}{l}\text { Category VI } \\
\text { Non-Erosive }\end{array}$ & Not applicable \\
\hline
\end{tabular}

difference in pressure between the top and the bottom of a rock block becomes large enough to overcome the weight and side friction on the block. Bollaert (2002) points out that brittle fracture and fatigue failure can contribute to breaking the rock into smaller pieces which then are carried away by the water. Note that most of the time, rock mass erosion will be the dominant process in rock erosion with only rare occurrences of rock substance erosion.

The critical velocity associated with rock erosion is much higher than the critical velocity associated with soil erosion in general. At the same time, the erosion rate for a given velocity is much lower for rock erosion than for soil erosion in general. Table 2 is an attempt at quantifying the critical velocity and the erosion rate of jointed rocks where the rock mass erosion may control the process. This table is preliminary in nature and should be calibrated against field behavior. The critical velocities quoted in Table 2 refer to the velocity necessary to move a particle with a size equal to the spacing between 


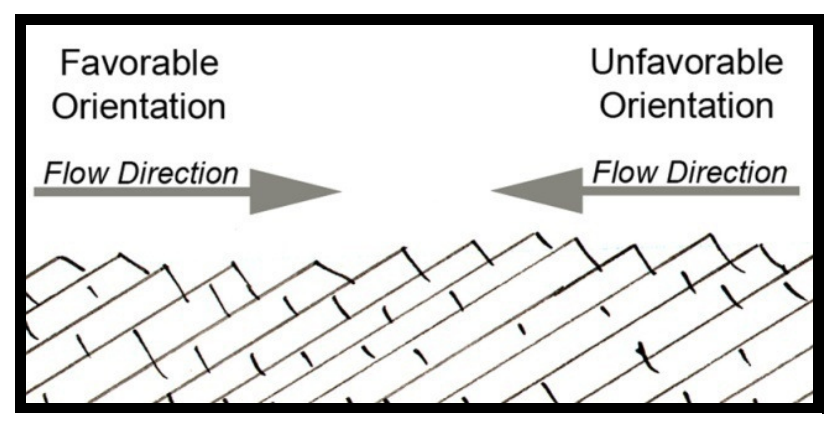

Fig.11 Effect of joint orientation on erosion resistance

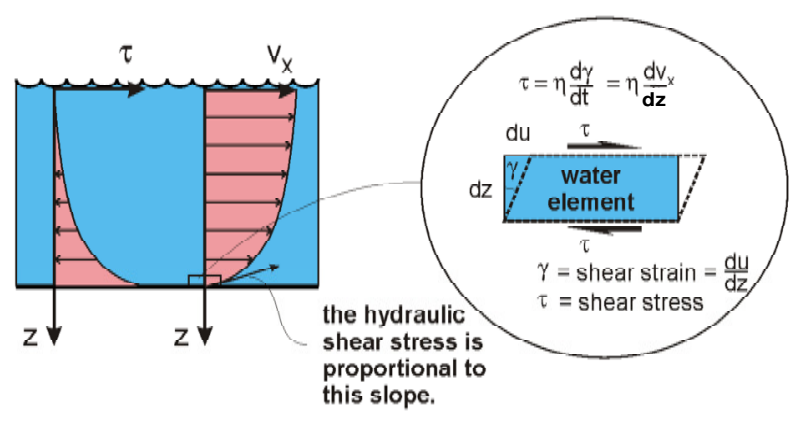

Fig.12 Velocity and shear stress profile versus flow depth

joints; as such they are likely lower bounds since they ignore any beneficial effect from the shear strength of the joints. Note that the orientation of the bedding of the rock mass is important as shown on Fig. 11. Engineering judgment must be used to increase or decrease the critical velocity when the bedding is favorable or unfavorable to the erosion resistance. In addition, it is highly recommended in all cases to measure the erosion function of the rock substance on core samples obtained from the site. This can be done with the EFA with or without circulation of sediments transported in the flow.

Examples of rock erosion rates can be collected from geology. For example, the Niagara Falls started about 12000 years ago on the shores of Lake Erie and have eroded back primarily through undercutting of the falls rock face to half way between Lake Erie and Lake Ontario. This represents $11 \mathrm{~km}$ and an average rate of $0.1 \mathrm{~mm} / \mathrm{hr}$, through sandstones, shales and limestones sedimentary rocks (http://en.wikipedia.or g/wiki/Niagara_Falls). Another example is the Grand Canyon where the Colorado River has generated $1600 \mathrm{~m}$ of vertical erosion through complex rock layers over an estimated 10 million years for an average rate of $0.00002 \mathrm{~mm} / \mathrm{hr}$ (http://en.wikipedia.org/wiki/Geology_of_the_Gran d_Canyon_area) as the Colorado Plateau was up-heaving. These rates appear negligible at first glance yet neglecting them would be neglecting the Grand Canyon or the retreat of Niagara Falls. The lesson is clear: it is not only the rate of erosion which is important but also the length of time over which that rate is being applied.

One may ask the question: "if a faucet drips on a pebble for 20 million years, will there be a hole in the pebble?" Common sense might lead to saying yes. Then the question might be: "how is it possible for a stress level as small as the one created by a drop of water to destroy the bonds of the rock". The answer may be that any stress no matter how small can defeat any strength no matter how large provided the number of cycles is high enough. Experiments to check such a statement would be very valuable.

\section{(3) Soil and rock erosion chart}

Fig. 6 and 7 are populated with soil and rock descriptions. The amount of data which led to placing soil and rock types in the various erosion categories is limited and goes against the statement made earlier that the relationship between the erosion function and common soil properties is poor. One other problem is that the relationship between water velocity and interface shear stress is not unique. Nevertheless, Fig. 6 and 7 were assembled based on EFA testing experience and other related experience. It is also based on the observation that grain size seems to control coarse grained soil erosion and that plasticity seems to have a significant influence on fine grain soil erosion. Fig. 6 and 7 are proposed as a starting point with the idea that further work may lead to adjustments and additions in the soil and rock descriptions within each category. Note that basically soils span categories I through IV while rocks span categories III through VI. To help quantify the potential error in using the charts, each measured curve in the data base which led to the charts was plotted on the chart to get the erosion category. The measured category for each soil was then compared to the predicted categories obtained by using the soil properties and the chart. The maximum error was one classification category up or down from the measurements. Such a chart may be used at the preliminary design stage to evaluate whether or not sampling and EFA testing is advantageous for final design. It is also important to remember that velocity alone is not as good an indicator of erodibility as shear stress and as such should be used with more caution and understanding than shear stress.

\section{(4) Water velocity}

Fig. 12 shows the profile of water velocity as a function of flow depth. The water velocity is largest near the top of the water column and zero at the bottom. This has been measured repeatedly in hydraulic engineering. By comparison, the shear 


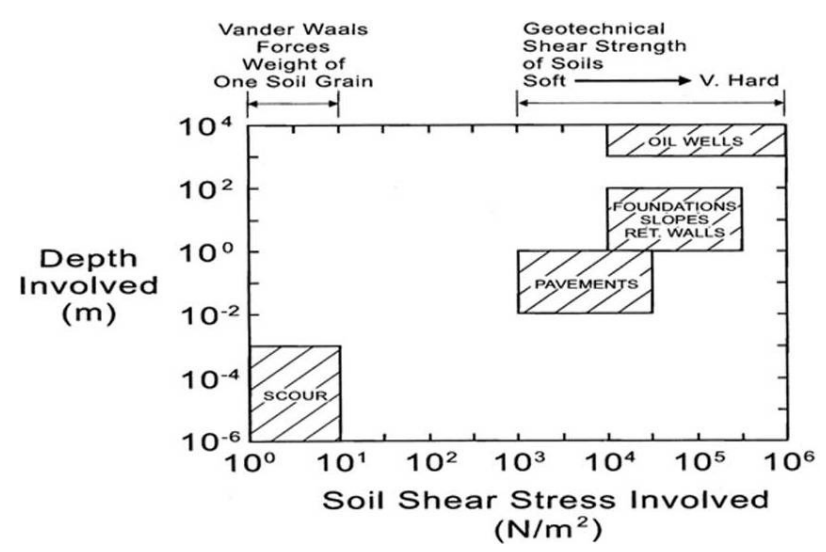

Fig.13 Range of shear stresses encountered in different engineering fields
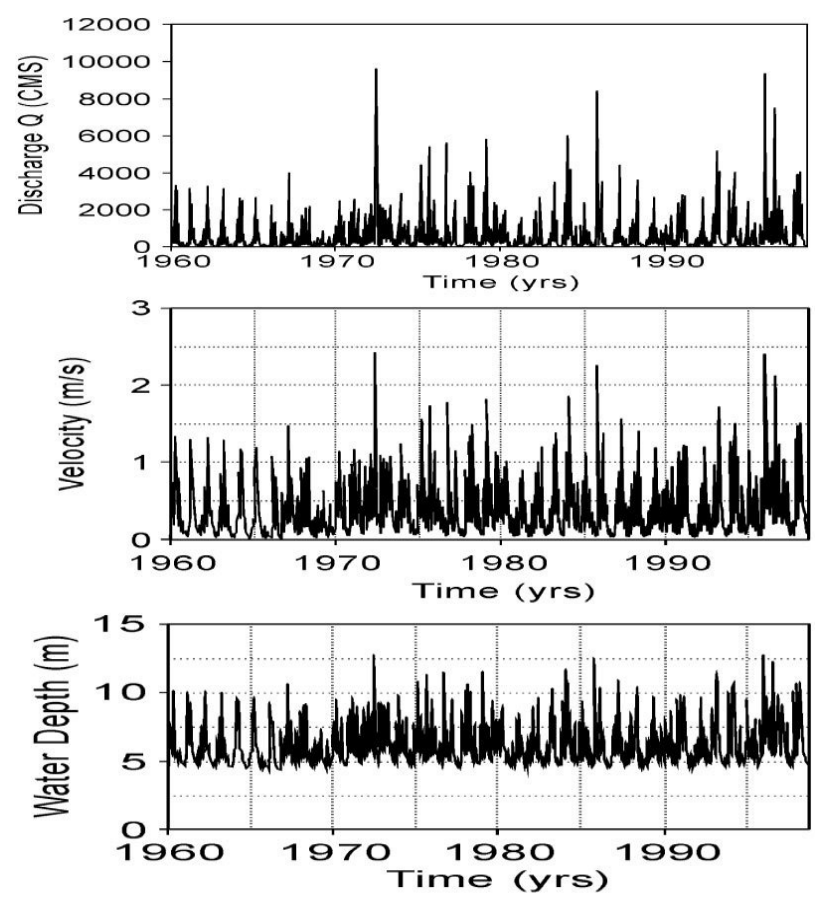

Fig.14 Discharge, velocity, and water depth hydrographs

stress is highest at the bottom and near zero at the top of the water column. The relationship between the shear stress and the velocity can be established as follows. Because water is a Newtonian fluid, there is a linear relationship between the shear stress $\tau$ and the shear strain rate $d \gamma / d t$.

$$
\tau=\eta\left(\frac{d \gamma}{d t}\right)
$$

Where $\eta$ is the viscosity of the water. Since, as shown on Fig. 12, $\gamma$ is $d u / d z$, then $d \gamma / d t$ is $d v / d z$ where $v$ and $u$ are the water velocity and horizontal displacement in the horizontal direction at a depth $z$ respectively. Then the shear stress at depth $z$ is given by:

$$
\tau=\eta\left(\frac{d v}{d z}\right)
$$

Therefore the shear stress is proportional to the gradient of the velocity profile with flow depth and the shear stress at the soil/rock-water interface is the slope of the profile at the interface. If the slope of the water velocity profile at the water-soil or water-rock interface (interface shear stress) is kept constant and if the water depth is varied, then it can be shown that the mean depth velocity will vary as well. This implies that there is no direct correspondence between mean depth velocity and interface shear stress. This is one reason why velocity alone is not as good a predictor of erosion as shear stress. As such, any erosion design tool presented in terms of velocity should be used with caution. On the other hand, velocity is much easier for the engineer to gage than shear stress, and this is why both velocity and shear stress are used in this paper.

The magnitude of these shear stresses is very small and measured in $\mathrm{N} / \mathrm{m}^{2}$. They are much smaller than the shear stresses that the geotechnical engineer is used to calculate in foundation engineering for example which are in the range of $\mathrm{kN} / \mathrm{m}^{2}$. Fig. 13 gives examples of the range of shear stresses associated with various fields of engineering. If the undrained shear strength is a reasonable measure of the strength of a clay for foundation engineering design, the critical shear stress is the "shear strength" of the same clay for erosion studies. The difference in magnitude of the stresses and the strengths for foundation engineering and erosion is that in erosion studies one looks at the resistance of one particle, or a small cluster of particles, while in foundation engineering one looks at the resistance of the soil mass at the foundation scale.

The water does not flow at a constant velocity in a river and the velocity history over a period of time is a necessary input to many erosion problems. This velocity history or hydrograph is not usually readily available. Often, the discharge $\left(\mathrm{m}^{3} / \mathrm{s}\right)$ hydrograph is available and needs to be transformed into a velocity $(\mathrm{m} / \mathrm{s})$ hydrograph and a water depth $(\mathrm{m})$ hydrograph. This is commonly done by using software such as HEC-RAS (Brunner, 2002). An example of the results of this transformation is shown in Fig. 14. HEC-RAS solves the one-dimensional energy equation for gradually varied flow in natural or constructed channels and adds the one-dimensional momentum equation around hydraulic structures such as bridges, culverts, and weirs where the energy equation is no longer applicable.

The hydrograph can be used to obtain the 100 year flood or the 500 year flood. One simple graphical 
Flood-frequency curve based on Original Hydrograph (1931-1999)

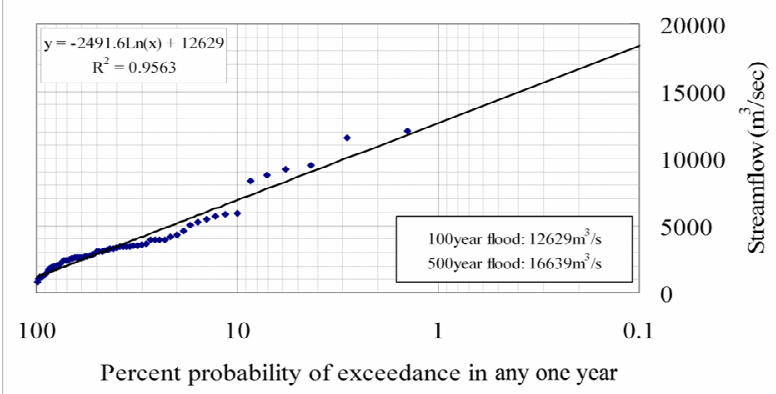

Fig.15 Flood frequency curve obtained from measured discharge hydrograph

method (e.g., Chow et al., 1988) consists of obtaining the yearly maximum flows from the hydrograph, ranking them in descending order of intensity, calculating for each flow the probability of exceedance as the rank divided by the total number of observations +1 , then plotting the flow versus the probability of exceedance on a semi-log paper such as the one of Fig. 15. Once the data is plotted, a linear regression is performed over 30 years of data and extrapolated to the 0.01 probability of exceedance for the 100 year flood and to the 0.002 probability of exceedance for the 500 year flood. Indeed the return period is the inverse of the probability of exceedance. There are other and more refined ways of obtaining these design floods but this simple graphical method helps understand the process and the meaning of the 100 year flood: a flood which has a $1 \%$ chance of exceedance in any one year. Fig. 15 shows the result of an analysis for the hydrograph at the Woodrow Wilson bridge. As can be seen on that figure, the 100 year flood has a discharge of 12,600 $\mathrm{m}^{3} / \mathrm{s}$ and the 500 year flood has a value of 16,600 $\mathrm{m}^{3} / \mathrm{s}$.

The probability of exceedance $R$ of the design flood with a given return period $T_{r}$ depends on the design life $L_{t}$ of a structure.

$$
R=1-\left(1-1 / T_{r}\right)^{L_{t}}
$$

If the design life of the bridge is 75 years, the probability that the flood with a return period of 100 year will be exceeded during the 75 year design life is 53\% according to Eq. 6 and that probability is $14 \%$ for the 500 year flood. Only when one gets to the 10,000 year flood does the probability get to be lower than $1 \%(0.75 \%)$. Therefore looking at those numbers alone, it seems desirable to use the 10,000 year flood for design purposes. This flood is used in design in the Netherlands for regions of the country deemed critical. The USA uses the 100 and 500 year flood for design purposes in hydraulic engineering; this leads to probabilities of exceedance which are in the tens of percent. By comparison, the structural engineers use a probability of exceedance of about $0.1 \%$ for the design of bridge beams (LRFD target) and, judging from measured vs. predicted pile capacity data bases (Briaud, Tucker, 1988) the geotechnical engineer uses a probability of exceedance of the order of a few percent. While these numbers can be debated, it is relatively clear that these different fields of civil engineering operate at vastly different probability of exceedance levels. There is a need to document these different levels, agree on a target level, and then operate at that common level. Note that risk is associated with the product of the probability of exceedance and the value of the consequence. As such, the probability of exceedance target should vary with the consequence of the failure.

\section{(5) Geometry of the Obstacle}

The geometry of the obstacle encountered by the water influences the velocity of the water and the flow pattern including turbulence intensity. When the water approaches a pier in a river it has to go around the pier. In doing so it faces a restricted area and has to accelerate to maintain the flow rate. This acceleration results in a local mean depth velocity which can be 1.5 times higher than the approach mean depth velocity. If the approach velocity is lower than the critical velocity but the local velocity around the pier reaches a value higher than the critical velocity, then scour occurs around the pier. This scour type is called clear water scour that is to say scour created by water which does not carry soil particles. On the other hand, if the approach velocity and the velocity around the pier are both higher than critical, then the scour type is live bed scour. This means that the water is carrying a significant amount of soil particles. The scour depth reached under live bed scour conditions is typically less than the scour depth reached under clear water scour conditions. The reason is that during live bed scour some of the particles in suspension fall down on the river bed thereby limiting the depth of the scour hole around the pier.

In order to evaluate the velocity and the shear stress created by an obstacle to the flow, it is convenient to use numerical simulations (e.g.: Chen, 2002). The CHEN 3D computer program (Chen 1995, Chen et al. 1998, 2000) is the program used by the author and his colleagues for such numerical simulations. First, the computational domain used to represent the flow, 
the soil or rock, and the obstacle is divided into a number of smaller grid blocks, which allow complex configurations and flow conditions to be modeled efficiently through the judicious selection of different block topology and boundary conditions. The chimera domain decomposition technique is used to connect the overlapped or embedded grids by interpolating information across the block boundaries. Then, the method solves the unsteady Reynolds-Averaged Navier-Stokes equations in general curvilinear coordinates $\left(\xi^{i}, t\right)$ :

$$
\begin{aligned}
& \frac{\partial \rho}{\partial t}+\left(\rho U^{m}\right)_{, m}=0 \\
& \begin{aligned}
\rho\left(\frac{\partial U^{i}}{\partial t}+U^{m} U_{, m}^{i}+R_{, m}^{i m}\right) & +2 \rho g^{i l} e_{l m n} \Omega^{m} U^{n} \\
& +\rho g_{m n}\left(\Omega^{i} \Omega^{m} \xi^{m}-\Omega^{m} \Omega^{n} \xi^{i}\right) \\
& =-g^{i m} p_{, m}+\left(\mu g^{m n} U_{, n}^{i}\right)_{, m}
\end{aligned}
\end{aligned}
$$

where $U^{i}$ and $u^{i}$ are contravariant components of the mean and fluctuating velocities, $p$ is pressure, $\Omega^{m}$ is the rotation vector. The Reynolds stress tensor $\boldsymbol{R}^{i j}=\overline{\boldsymbol{u}^{i} \boldsymbol{u}^{j}}$ is the solution of the transport equations

$$
\begin{aligned}
\frac{\partial R^{i j}}{\partial t}+ & U^{m} R_{, m}^{i j} \\
& =P^{i j}+D_{u}^{i j}+D_{p}^{i j}+D_{v}^{i j}+\Phi^{i j}-\varepsilon^{i j}
\end{aligned}
$$

where $P^{i j}=-\left(R^{i m} U_{, m}^{j}+R^{j m} U_{, m}^{i}\right)-2 e_{l m n} \Omega^{m}\left(g^{i l} R^{j n}+g^{j l} R^{i n}\right)$ is the production term, $\boldsymbol{D}_{u}^{i j}=-\left(\overline{\boldsymbol{u}^{i} \boldsymbol{u}^{j} \boldsymbol{u}^{m}}\right)_{, m}$ is the diffusion by $u^{m}, D_{p}^{i j}=-g^{j m}\left(\overline{u^{i} p^{\prime} / \rho}\right)_{, m}-g^{i m}\left(\overline{u^{j} p^{\prime} / \rho}\right)_{, m}$ is the diffusion by $p^{\prime}, \boldsymbol{D}_{v}^{i j}=\boldsymbol{v} \boldsymbol{g}^{m n} \boldsymbol{R}_{, m n}^{i j}$ is the viscous diffusion term, $\Phi^{i j}=\overline{\left(p^{\prime} / \rho\right)\left(g^{i m} u_{, m}^{j}+g^{j m} u_{, m}^{i}\right)}$ is the pressure-strain term, and $\boldsymbol{\varepsilon}^{i j}=\mathbf{2} \boldsymbol{v} \boldsymbol{g}^{m n} \overline{\boldsymbol{u}_{, m}^{i} \boldsymbol{u}_{, n}^{j}}$ is the viscous dissipation term.

To solve these equations, appropriate closure models must be provided for the pressure-strain, diffusion and dissipation terms. In the second-moment closure model, the diffusion terms by $u^{m}$ and $p^{\prime}$ are represented by using the gradient-diffusion model:

$$
D^{i j}=D_{u}^{i j}+D_{p}^{i j}=C_{s}^{\prime}\left(\frac{k}{\varepsilon} R^{m n} R_{, n}^{i j}\right)_{, m} ; C_{s}^{\prime}=0.22
$$

The pressure strain and viscous dissipation terms are also modeled together as follows:

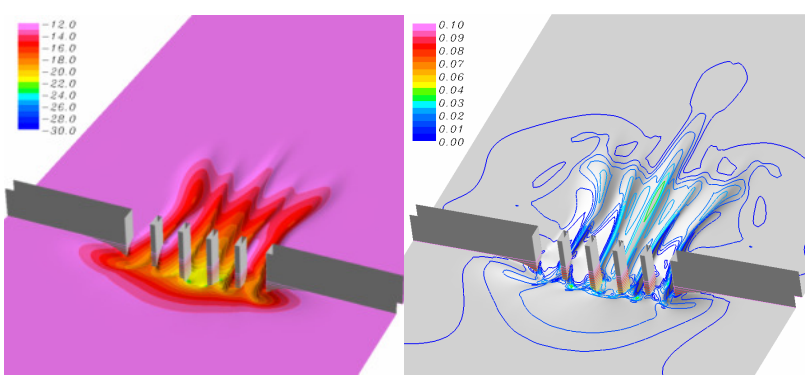

(a) Scour depth and shear stress distributions at $\mathrm{t}=2000 \mathrm{~min}$

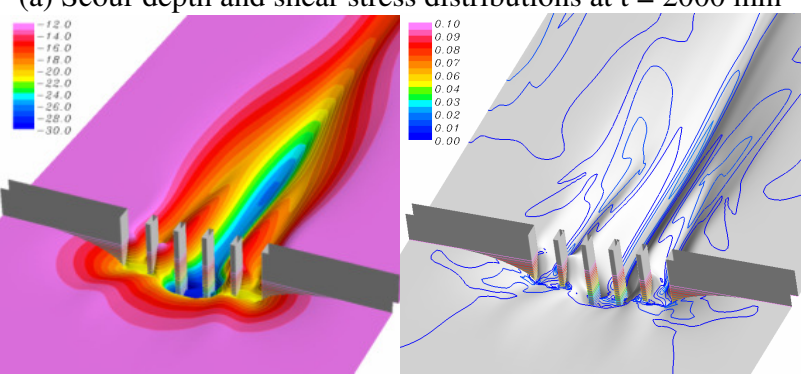

(b) Scour depth and shear stress distributions at $\mathrm{t}=15000 \mathrm{~min}$

Fig.16 Predicted scour hole shape and streambed shear stresses around abutments and piers: (a) $\mathrm{t}=2000 \mathrm{~min}$, (b) $\mathrm{t}=$ 15000 min (From Chen, 2002)

$$
\begin{aligned}
\Phi^{i j}- & \varepsilon^{i j}=\bar{\Phi}_{1}^{i j}+\bar{\Phi}_{2}^{i j}+\bar{\Phi}_{w}^{i j}-\frac{2}{3} g^{i j} \mathcal{E} \\
\bar{\Phi}_{1}^{i j}=- & \bar{C}_{1}\left\{1-\left(1-\frac{1}{\bar{C}_{1}}\right) f_{w}\right\} \varepsilon b^{i j} \\
& +\bar{C}_{2}\left(1-f_{w}\right) \varepsilon\left(g_{m n} b^{i m} b^{j n}-\frac{1}{3} g^{i j} I I\right) \\
\bar{\Phi}_{2}^{i j}=\left(C_{3}-C_{3}^{*} I I^{1 / 2}\right) k S^{i j} & \\
+ & C_{4} k\left(g_{m n} b^{i m} S^{j n}+g_{m n} b^{j m} S^{i n}-\frac{2}{3} g^{i j} I I\right) \\
& +C_{5} k\left(g_{m n} b^{i m} W^{j n}+g_{m n} b^{j m} W^{i n}\right) \\
\bar{\Phi}_{w}^{i j}=f_{w} & \left\{0.45\left(P^{i j}-\frac{2}{3} g^{i j} P\right)\right. \\
& \left.-0.03\left(Q^{i j}-\frac{2}{3} g^{i j} P\right)+0.08 k\left(2 S^{i j}\right)\right\}
\end{aligned}
$$

A more detailed description of the near-wall second-moment closure is given in Chen (1995) and Chen et al. (2000). In addition to the above near-wall second-moment closure model, several isotropic eddy viscosity models including the two-layer $k-\varepsilon$ model (Chen and Patel, 1988), RNG $k$ - $\varepsilon$ model, and other low Reynolds number $\mathrm{k}-\varepsilon$ models are also incorporated in CHEN 3D. From the computational point of view, the mean flow and turbulence quantities are calculated using the finite-analytical method of Chen, Patel, and Ju (1990). 

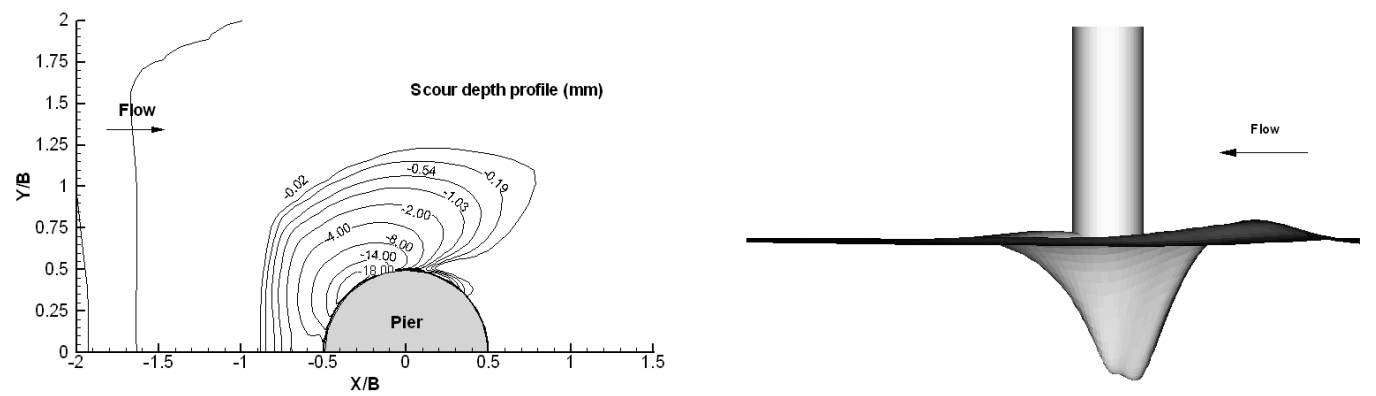

(a) Erosion rate determined solely by streambed shear stress
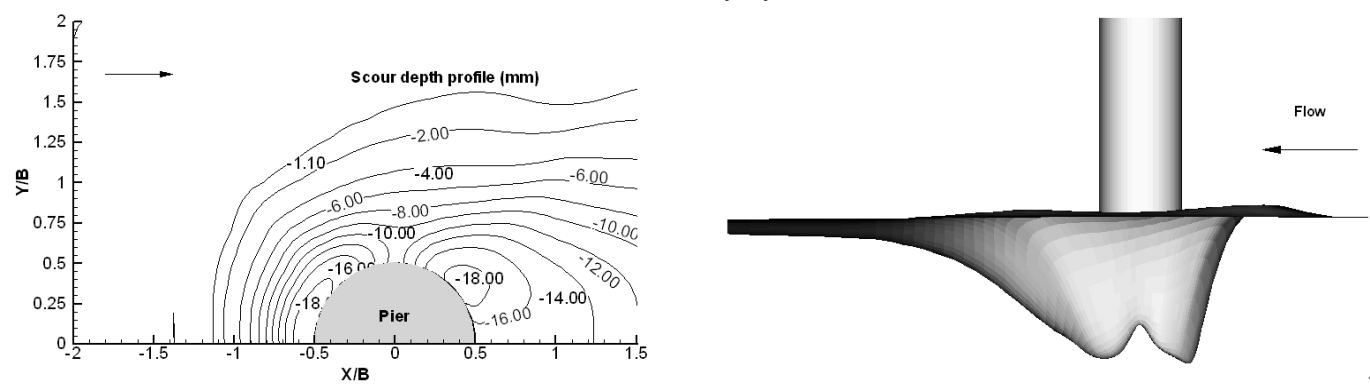

(b) Erosion rate determined by streambed shear stress and turbulent kinetic energy
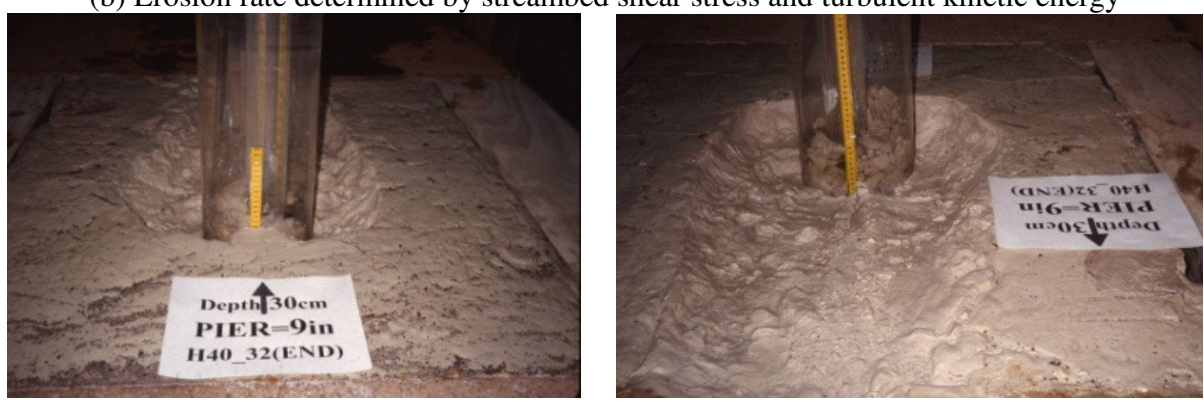

(c) Experiment on a $230 \mathrm{~mm}$ diameter pier: upstream view, downstream view

Fig.17 Scour hole pattern: (a) simulation without turbulence term in model, (b) simulation with turbulence term in model, (c) observed scour hole around a $230 \mathrm{~mm}$ diameter pier.

The free surface boundary conditions for viscous flow consist of one kinematic condition and three dynamic conditions. The kinematic condition ensures that the free surface fluid particles always stay on the free surface:

$$
\eta_{t}+U \eta_{x}+V \eta_{y}-W=0 \text { on } \quad z=\eta
$$

where $\eta$ is the wave elevation and $(U, V, W)$ are the mean velocity components on the free surface. The dynamic conditions represent the continuity of stresses on the free surface. When the surface tension and free surface turbulence are neglected, the dynamic boundary conditions reduce to zero velocity gradient and constant total pressure on the free surface.

The Erosion Rate Equations describe the behavior of the soil-rock at the soil-rock/water interface. The simplest form is given by:

$$
\frac{\dot{Z}}{u}=\alpha\left(\frac{\tau-\tau_{c}}{\rho u^{2}}\right)^{m}
$$

where $\dot{Z}$ is the erosion rate $(\mathrm{m} / \mathrm{s}), \mathrm{u}$ the water velocity $(\mathrm{m} / \mathrm{s}), \tau$ the hydraulic shear stress $\left(\mathrm{N} / \mathrm{m}^{2}\right)$, $\tau_{c}$ the threshold or critical shear stress below which no erosion occurs $\left(\mathrm{N} / \mathrm{m}^{2}\right), \rho$ the mass density of water $\left(\mathrm{kg} / \mathrm{m}^{3}\right)$, and $\alpha$ and $m$ are constants characterizing the soil and obtained by testing in the EFA. If the effect of turbulence is to be investigated, a second term $\beta k$ can be added to equation 16 (Nurtjahyo, 2003). This term is the product of a soil or rock characteristic $\beta$ and the dimensionless turbulent kinetic energy $k$ (Chen and Patel, 1988). Work is ongoing to obtain $\beta$ from EFA tests.

During each time step, the incremental erosion movement at each point along the soil-rock/water boundary is computed using the erosion rate equation. After the new erosion depth distribution is obtained, the coordinate of each bed point is updated 


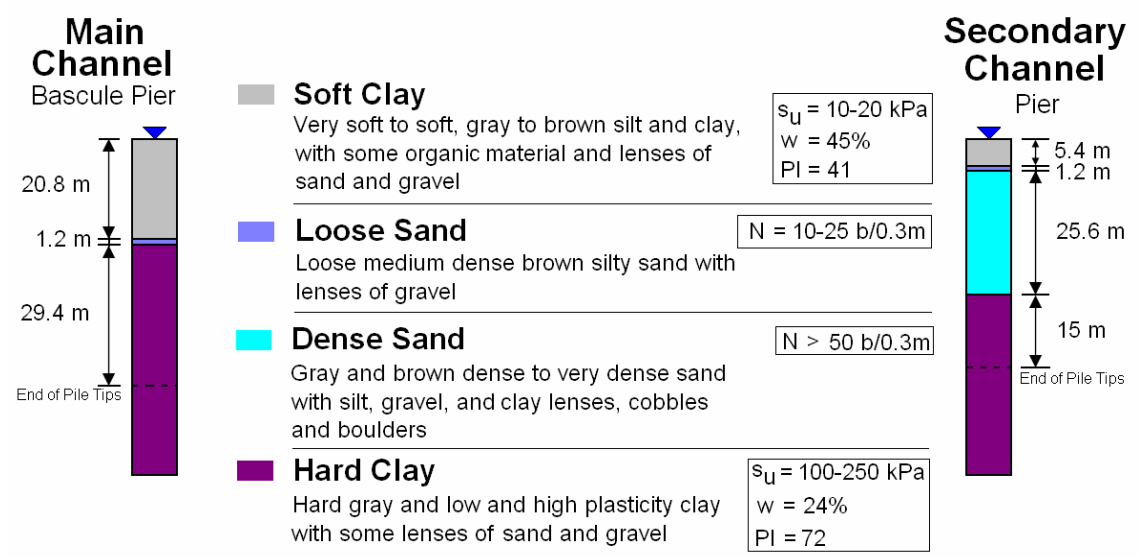

Fig.18 Soil stratigraphy at the location of the New Woodrow Wilson Bridge
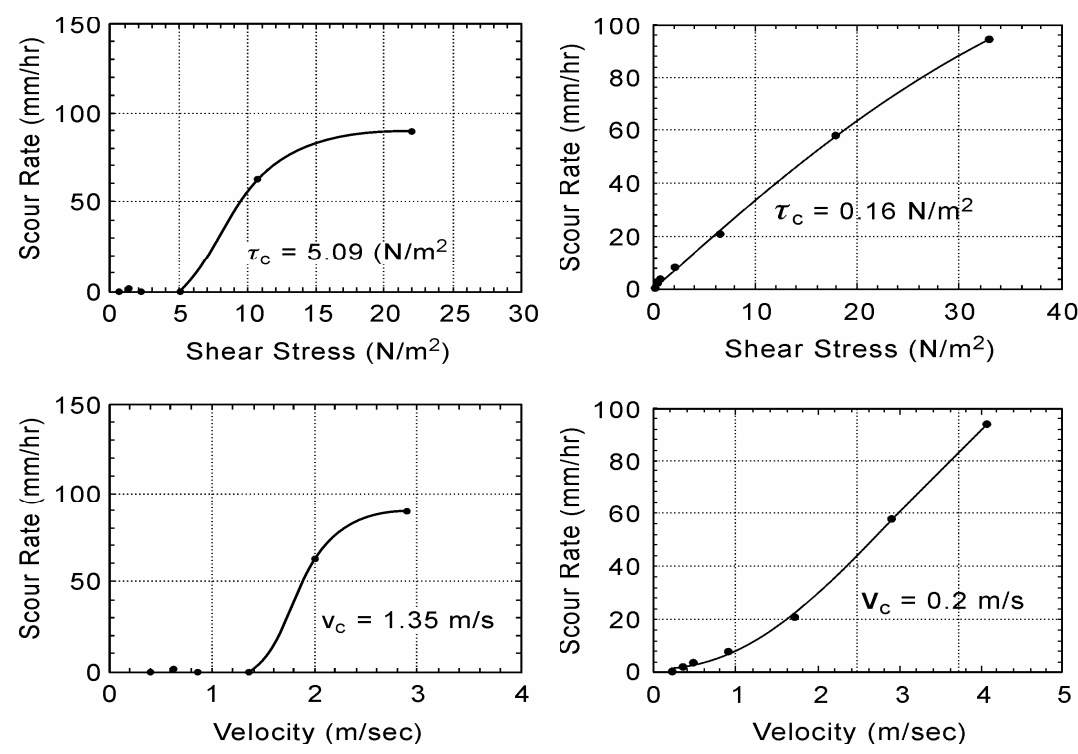

Fig.19 Erosion functions for the two main soil layers at the main pier location

and the soil water interface is moved to the new elevation. The numerical grids are then adjusted vertically to conform to the updated bathymetry of the eroded surface. Examples of the output of such 3D simulations are presented in Fig. 16 where the river bottom contours and the shear stress contours are shown. Fig. 17 shows the difference between including and not including the effect of turbulence in the erosion model. As can be seen in Fig. $17 \mathrm{a}$ and $\mathrm{b}$, the addition of the turbulence term does not make much difference on the scour pattern in areas where the turbulence intensity is small (in front and to the side of the pier) but does make a significant difference in areas where the turbulence is intense (behind the pier). This is corroborated by the experiment shown in Fig. 17c. Note that in this case, while the scour hole pattern is significantly different with and without the turbulence term, the predicted scour depth is essentially the same. Once all the information on the components of the problem are assembled (soil, water, and geometry), the goal of an erosion problem is to predict the rate of erosion as a function time over the period of interest. The following are four case histories showing examples of soil and rock erosion.

\section{THE WOODROW WILSON BRIDGE CASE HISTORY (Kwak et al. 2002)}

Bridge scour accounts for $60 \%$ of all bridge failures in the USA (Briaud, 2006a). The following case history describes the process followed to evaluate the scour depth around the main pier of the New Woodrow Wilson Bridge which carries I-95 across the Potomac River in Washington D.C.

\section{(1) Soil erodibility}

The soil stratigraphy is presented on Fig. 18. It shows that at the location of the main pier in the main channel, the soil stratigraphy is made of a soft 


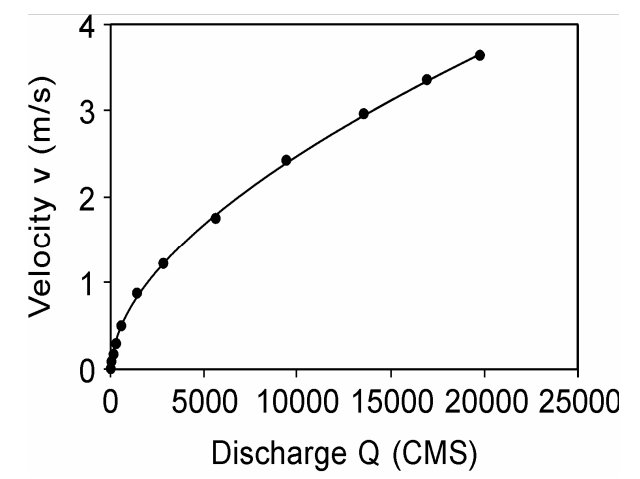

Fig.20 Calculated relationship between river discharge and the velocity at the Woodrow Wilson Bridge if the bridge was not there

organic clay over laying a layer of hard plastic clay. Twelve ASTM Standard thin wall steel tube samples were collected at the bottom of the Potomac River and sent to Texas A\&M University for EFA testing. Examples of the erosion functions obtained for samples close to the main pier are shown on Fig. 19. As can be seen the soft layer has a much higher critical velocity than the hard clay below giving another example that critical velocity does not necessarily increase with shear strength.

\section{(2) Water velocity}

The nearest gaging station (Gage Station 01646500; www.usgs.gov) on the Potomac River is located approximately $13 \mathrm{~km}$ upstream of the Woodrow Wilson Bridge and has a drainage area of $29,965 \mathrm{~km}^{2}$. The discharge hydrograph from this gage station was multiplied by the drainage area ratio between the bridge location and the gage location (30742/29965) to obtain the discharge hydrograph at the bridge (Fig. 14). The program HEC-RAS (Hydrologic Engineering Center's River Analysis
System) (Brunner, 2002) is a commonly used 1D flow analysis program. It was used to develop the relationship between the discharge and the velocity (Fig. 20) on one hand and the discharge and the water depth on the other. Note that the velocity on Fig. 14 and 20 is the velocity of the water at the main pier location if the bridge was not there. Indeed it is that velocity, also called approach velocity, which is used in pier scour depth calculations. Using these relationships, the discharge versus time curve was transformed into the water depth hydrograph and into the velocity hydrograph or velocity versus time curve (Fig. 14).

Also necessary in the scour depth prediction process are the discharge for the design floods namely the discharge for the 100 year flood and for the 500 year flood. To obtain these two design discharges, the procedure described earlier was followed and the graph of Fig. 15 was obtained. The design discharges were read on that graph for a percent probability of exceedance in any one year equal to $1 \%$ for the 100 year discharge $\left(12629 \mathrm{~m}^{3} / \mathrm{s}\right)$ and equal to $0.2 \%$ for the 500 year discharge (16639 $\left.\mathrm{m}^{3} / \mathrm{s}\right)$.

\section{(3) Geometry of the obstacle}

The New Woodrow Wilson Bridge is a bascule bridge and the obstacle to the flow considered for this case history is the main bascule pier for the bridge (Fig. 21). As can be seen, the pier is very large and complex with a column, a pile cap, and a group of piles.

\section{(4) Scour depth calculations}

The scour depth was predicted by several groups. The Texas A\&M University group used the SRICOS-EFA method (Briaud et al. 1999, 2001a,

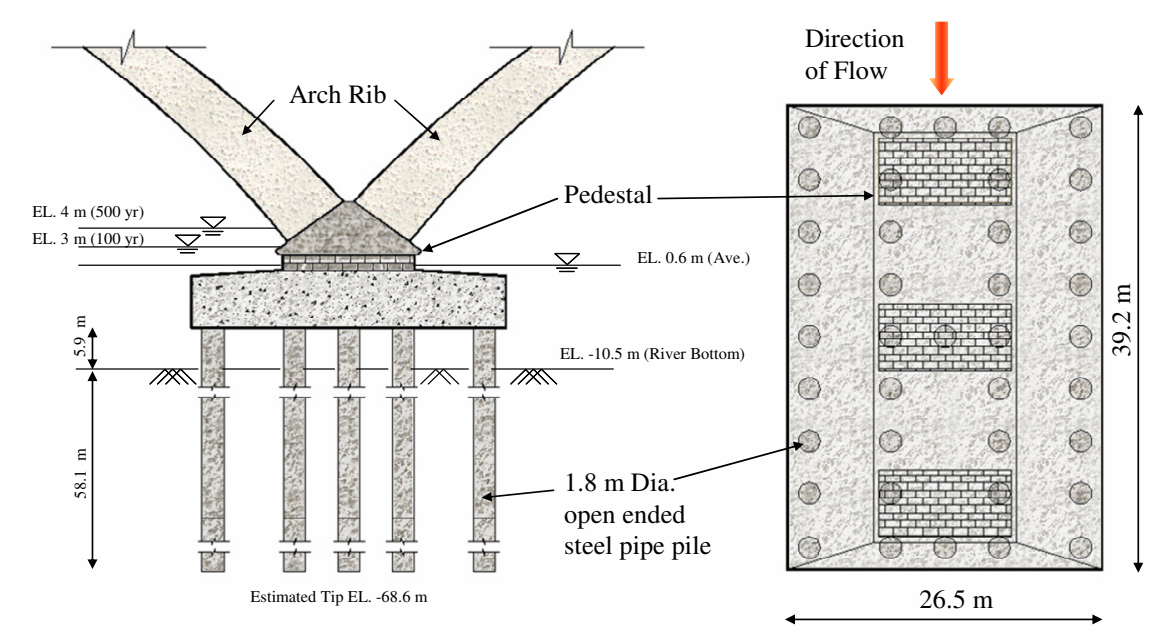

Fig.21 Bascule Pier M1 of the new Woodrow Wilson Bridge 

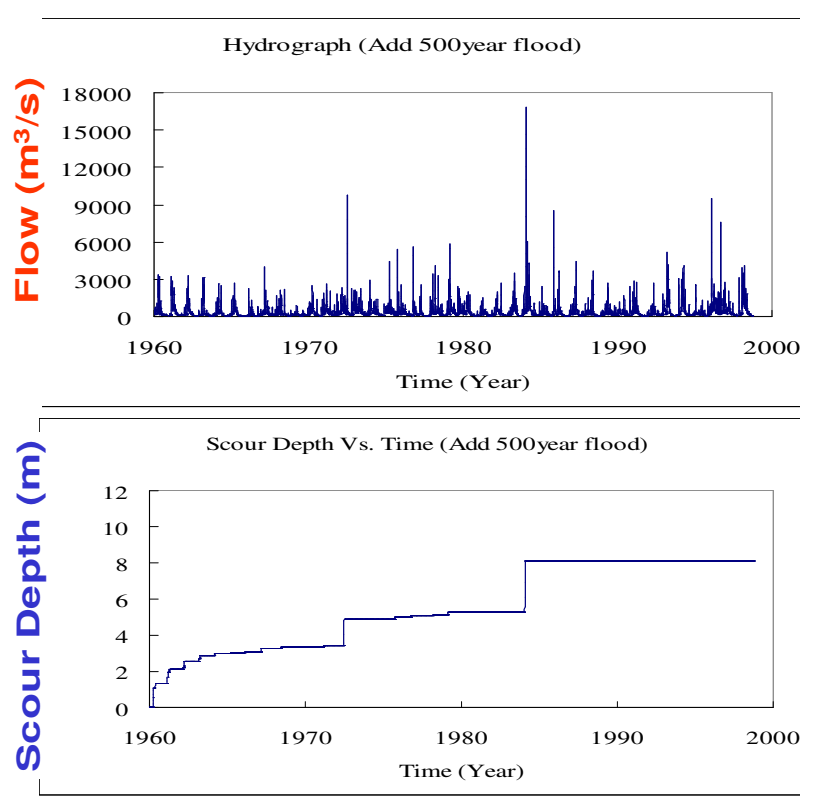

Fig.22 Scour depth vs. time for the main pier of the Woodrow Wilson Bridge

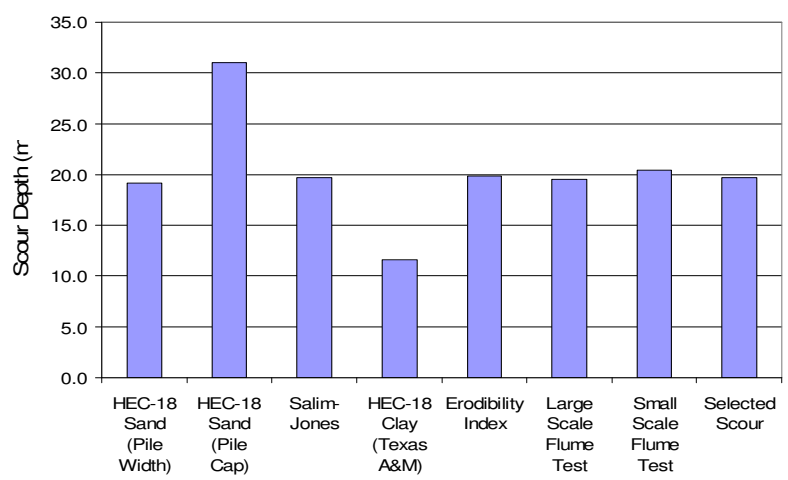

Fig.23 Scour depth predictions for the main pier of the Woodrow Wilson Bridge

2001b, 2004a, 2004b, 2005, http://ceprofs.tamu.edu /briaud/). This method is part of the FHWA national guidelines for scour predictions (Richardson, Davis, 2001, commonly referred to as HEC-18) and will be called "HEC-18 clay". In this method the soil is characterized by the erosion functions of the various layers measured on a site specific basis with the EFA, the water input consists of the water depth hydrograph and the velocity hydrograph over the design period, and the geometry is described by an equivalent single pier (Kwak et al. 2002). An example prediction including a 500 year design flood is shown on Fig. 22. Note that HEC-18-Clay predicts the final scour depth, $Z_{\text {final }}$, at the end of the hydrograph. Most other methods predict the maximum scour depth, $Z_{\max }$, for the design flood. Using $Z_{\max }$, as a prediction assumes that the design flood will last long enough to erode the soil to the maximum scour depth for that velocity; this is a

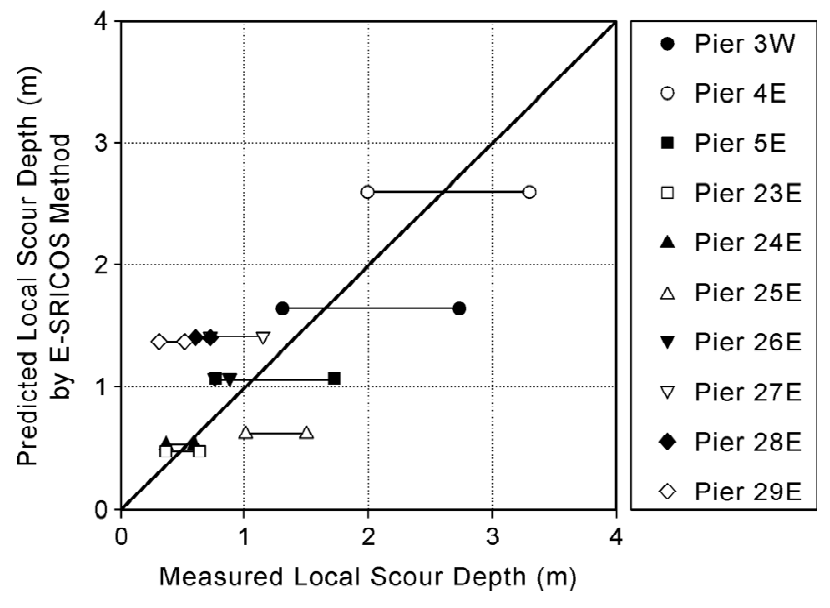

Fig.24 Predicted vs. measured scour depths at the old Woodrow Wilson Bridge

reasonable assumption for a fine sand but not for a soil with a slow erosion rate. In those less erodible soils, $Z_{\text {final }}$ is often much less than $Z_{\max }$ and it is advantageous to use HEC-18-Clay rather than HEC-18-Sand.

Other engineers predicted the maximum scour depth according to various methods (Davis, 2001, Fig. 23). HEC-18 Sand (Richardson and Davis, 2001) makes the assumption that the soil is fine sand. It was used with two geometry considerations: one using the single equivalent pier diameter approach, and one using the width of the pile cap as the width of the pier. The Salim-Jones method (Salim, Jones, 1998) was used as a method which takes better account of the true shape of the foundation by adding the scour depth created by the piles, by the pile cap, and by the column above it; this method also assumes that the soil is fine sand. The erodibility index method is a method which uses an index as the threshold for scour and erosion of earth materials (Annandale, 1995, 2000). Scaled laboratory models using fine sand to represent the soil were performed at a small scale and at a larger scale; both results were extrapolated to full scale using similitude laws and gave the results on Fig. 23.

As can be seen, most results were quite consistent with predicted scour depths around $20 \mathrm{~m}$, except for the HEC-18-Clay method which predicted about half that scour depth. This may not come as a surprise since HEC-18-Clay is the only method which was based on the measured erosion functions of the clay layers at the site. In order to further investigate this discrepancy in the predictions, HEC-18-Clay was used to predict the scour depths at the old Woodrow Wilson Bridge piers where measured values were available (Hunt, 2001). The very favorable comparison obtained between predicted and measured values (Fig. 24) (Kwak et al. 2002) gave 


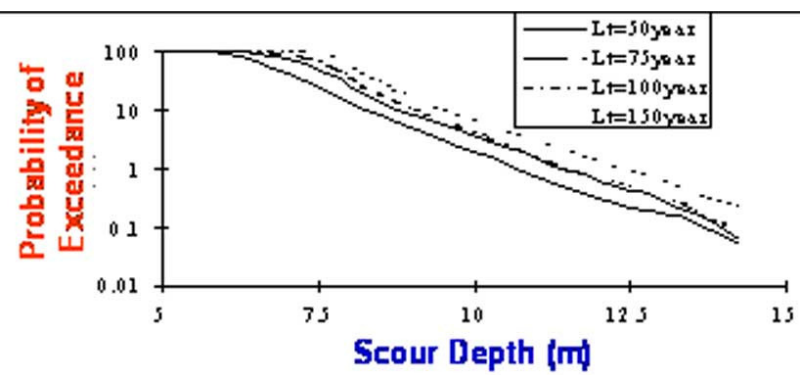

Fig.25 Probability of exceedance over the design life vs. scour depth curve

more credibility to the HEC-18-Clay predictions for the new bridge.

\section{(5) Probabilistic scour calculations}

The HEC-18-Clay method also allows the user to develop a probability of exceedance $P$ vs. scour depth $\mathrm{Z}$ curve so that the engineer can chose a scour depth corresponding to an acceptable probability of exceedance. The steps to develop the $\mathrm{P}-\mathrm{Z}$ curve are as follows (Brandimarte et al. 2006, Briaud et al., 2007, Bolduc et al., 2008). First, the flow values in the hydrograph for the chosen period of time are organized in a log normal cumulative distribution function. Second, a random number generator is used to sample that distribution and create, say, 1000 equally likely future hydrographs. Third, for each of these 1000 future hydrographs, the final depth of scour, $\mathrm{Z}_{\text {final }}$, is obtained according to HEC-18-Clay. Fourth, the 1000 values of $Z_{\text {final }}$ are organized in a $\log$ normal distribution and presented as a cumulative density function referred to earlier as the $\mathrm{P}-\mathrm{Z}$ curve. This process is an integral part of the SRICOS-EFA computer program (Kwak et al., 2001, http://ceprofs.tamu.edu/briaud/). Fig. 25 is an example of a P-Z curve. With this graph, the engineer can decide at what probability of exceedance to operate and choose the corresponding scour depth.

\section{THE BRAZOS RIVER MEANDER CASE HISTORY (Park, 2007)}

The erosion associated with the migration of river meanders has a major impact on embankments and bridges worldwide. Many have contributed to the advancement of knowledge in this field including Brice (1974), Hickin and Nanson (1984), Hooke (2001) and W. de Moor et al. (2007). The following case history describes a prediction process used to evaluate the migration of a meander of the Brazos River near Navasota, Texas (Fig. 26).

\section{(1) Observations}

Records indicate that the meander has migrated significantly and rather steadily over a long period of time. Fig. 26, 27, and 28 document the amount of migration which is of the order of $4 \mathrm{~m} / \mathrm{yr}$. Observations at the site and large scale laboratory experiments at Texas A\&M University (Wang, 2006, Park, 2007, Yeh, 2008) indicate that the process by which the meander progresses is erosion of the base of the river bank which undercuts the steep slopes and leads to overhang failures of the banks. The material which falls into the flow is then moved to the other side of the main channel and slightly downstream. This cross channel movement is due to the helical flow of the water in the meander. Such helical flow has been experimentally measured and numerically reproduced (Yeh, 2008, Briaud et al., 2007a). This process leads to the formation of sand beaches on the inside of the meander and to steep banks on the outside of the channel.

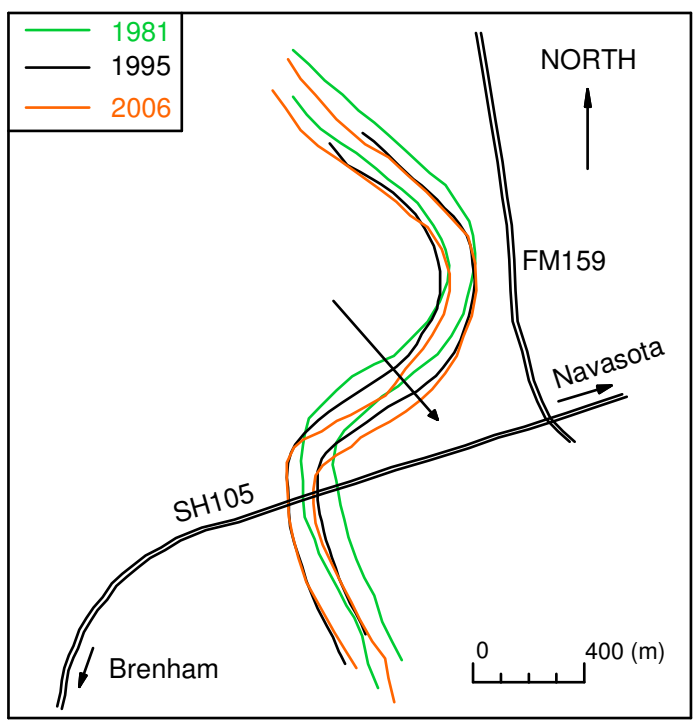

Fig.26 Measured migration of the meander over a 25 year period

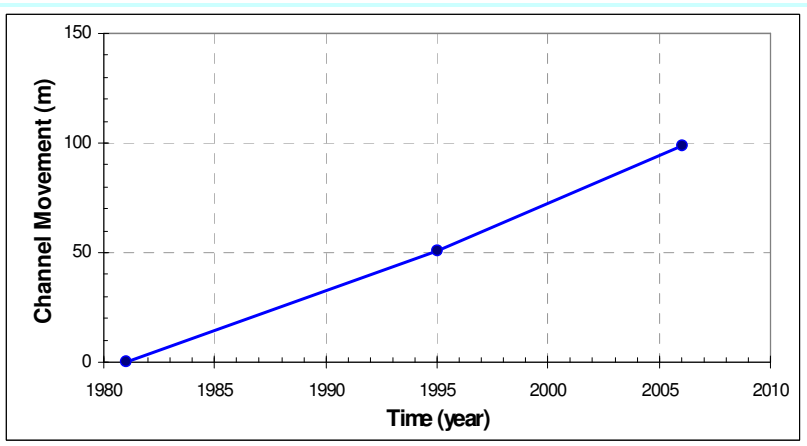

Fig.27 Meander migration as a function of time along the arrow of Fig. 26 


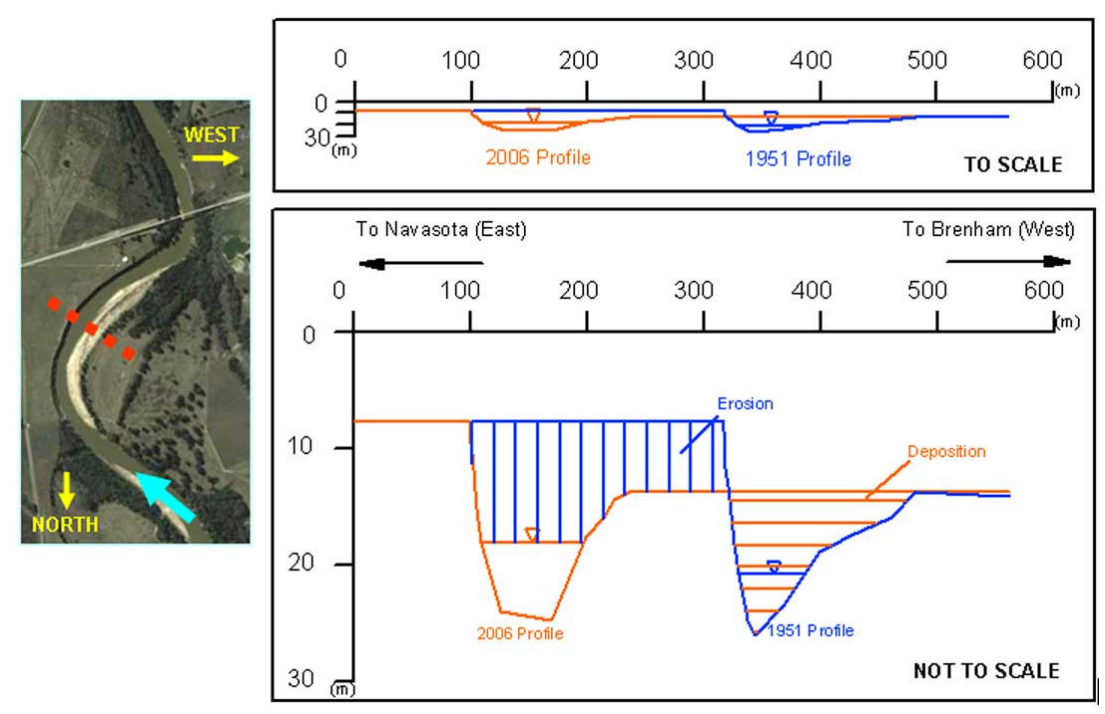

Fig.28 Lateral movement of the main channel between 1951 and 2006
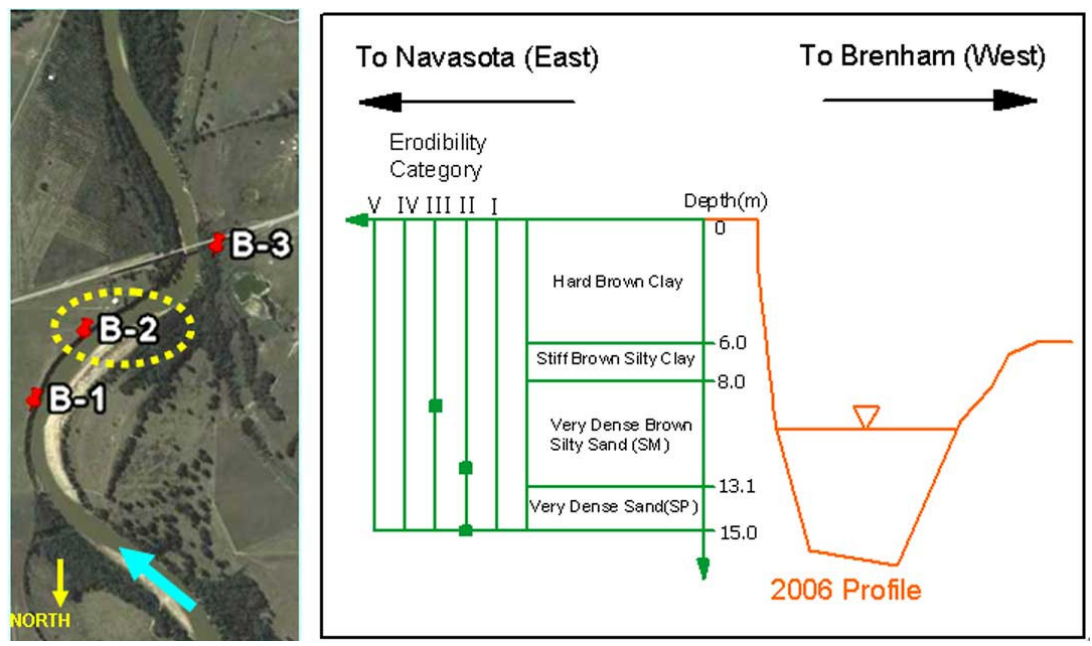

Fig.29 Soil stratigraphy at boring B-2

\section{(2) Soil erodibility}

Borings were drilled at the site of the meander from the top of the bank. The stratigraphy according to boring B-2 (Fig. 29) shows $8 \mathrm{~m}$ of clay underlain by 7 $\mathrm{m}$ of sand. Thin wall steel tube samples were collected and tested in the EFA. The results are shown in Fig.30. As can be seen the deeper samples in boring B-2 are more erodible (Category 2) than the shallow one (Category 3 ). This means that the sand layer below will erode faster than the clay layer above. This will undercut the overhanging clay and lead to sloughing as observed in the field. The prediction of meander migration was made using the erosion function of the deeper sand layer since it was the controlling layer in this case.

\section{(3) Water velocity}

Gage station ST\# 08110200 is located at the SH105 Bridge over the Brazos River very close to the meander where the data was necessary. This gage worked from 1965 to 1987 . In order to obtain the hydrograph over the prediction period 1958 to 2006, a process was developed (Park, 2007) to make use of other nearby stations which had longer records (ST\# 08110200, ST\# 08108700, and ST\# 08109000). Then the relationship between discharge, velocity, and water depth was obtained from the actual measurements made during the period of 1965 to 1987 at gage ST\# 08110200. The velocity hydrograph of Fig. 31 was finally obtained.

\section{(4) Geometry of the obstacle}

In this case, the obstacle is the shape of the meander which is characterized primarily by its radius of curvature $R$ and the width of the river channel W. In order to obtain R, a circle is fitted to the meander and the radius of the best fit circle is retained as the value of R. The bend angle $\Phi$ is the angle to the center of that circle bounded by the beginning of the meander $\mathrm{B}$ and the end of the 


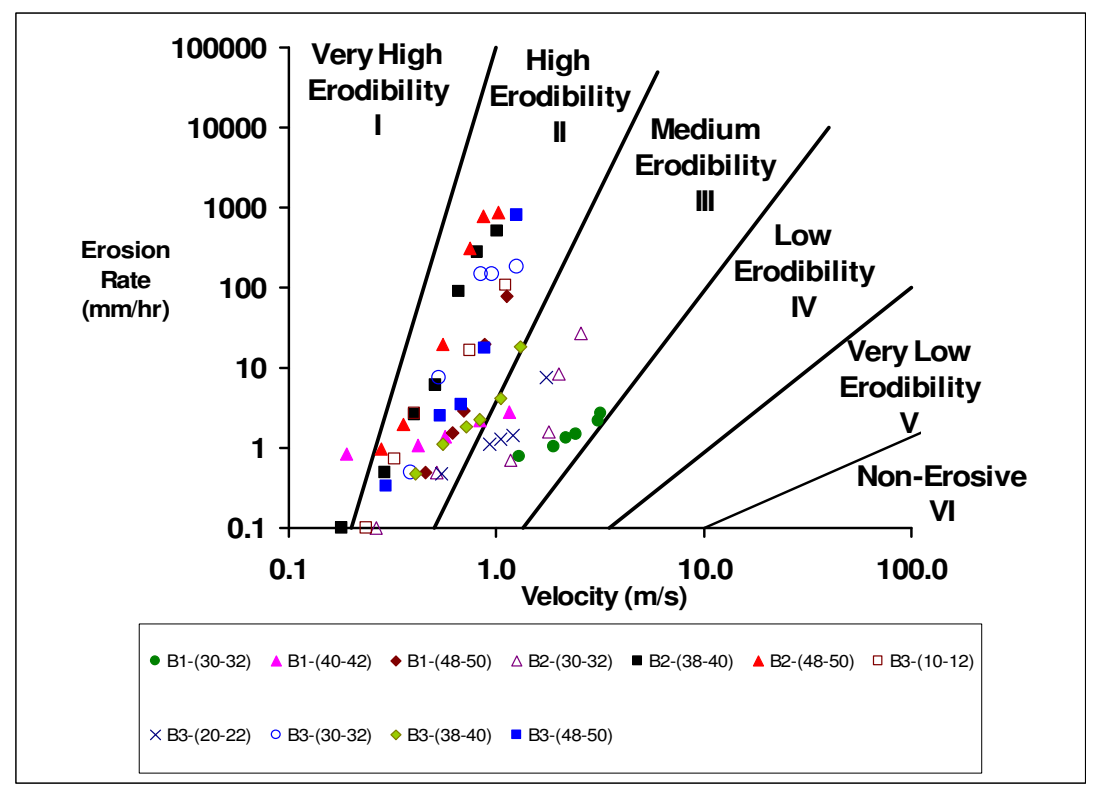

Fig.30 EFA test results on the soil from the meander bank

meander $\mathrm{E}$ on that circle. Any point $\mathrm{M}$ on the meander is then identified by the angle $\theta$ between $\mathrm{B}$ and $M$. Migration of the meander at point $M$ is

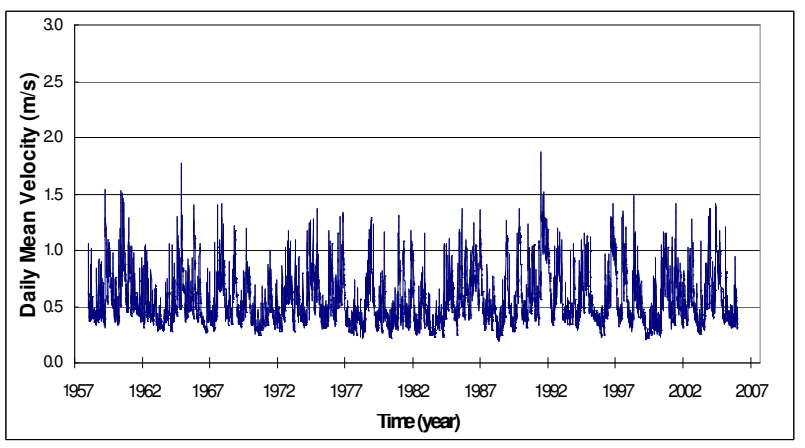

Fig.31 Velocity hydrograph for the Brazos River meander

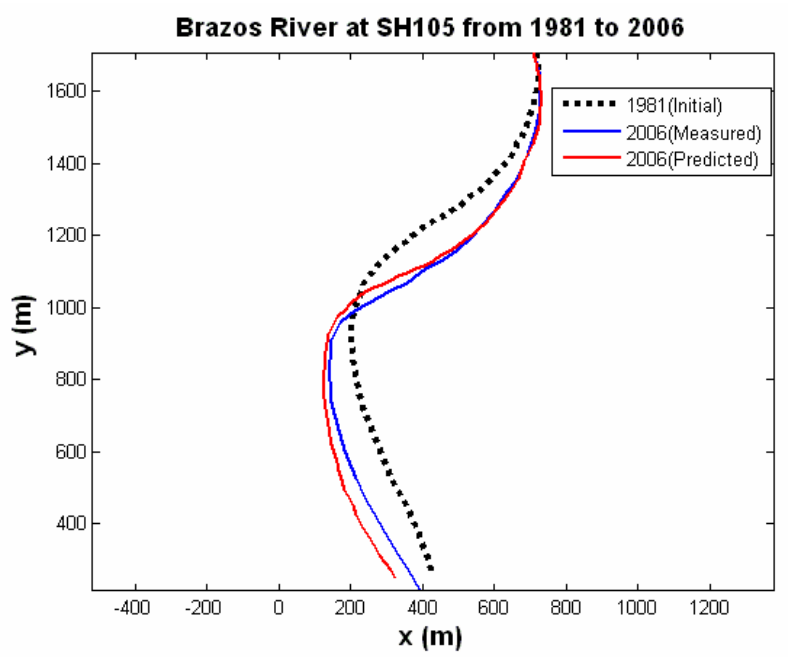

Fig.32 Predicted and measured migration of the Brazos River from 1981 to 2006 predicted as the movement over a period of time in the direction of the circle radius.

\section{(5) Meander migration calculations}

A method including free software (http://ceprofs.tamu.edu/briaud/) was developed to predict the migration of a meander over a long period of time (Briaud et al, 2007a, Wang, 2006, Park, 2007, Yeh, 2008). This method is based on a model which gives the migration rate as a function of the soil erodibility, the water velocity, and the meander geometry. It consists of fitting the river reach with a set of circles and straight lines, and then stepping into time while accumulating the migration of each point along the circles due to each velocity. This process was followed for the Brazos River meander and led to the prediction shown in Fig. 32. As can be seen the prediction is very good for locations B-1 and B-2 on Fig. 27 but not as good for location B-3. The difference between these locations is that at locations B- 1 and B-2 the bank is barren, while the bank at B-3 is lined with trees and some rock-fill to protect the bridge. As a result the erosion function used in the prediction is not the correct function for location B-3 yet it is conservative.

\section{(6) Probabilistic migration calculations}

The method developed to predict meander migration was extended to include the probability that the river would reach a certain point or further. In order to do that, the process followed for the probability of exceedance of a scour depth in the case of bridge scour was also followed for the migration of a meander. The velocity values of the hydrograph 


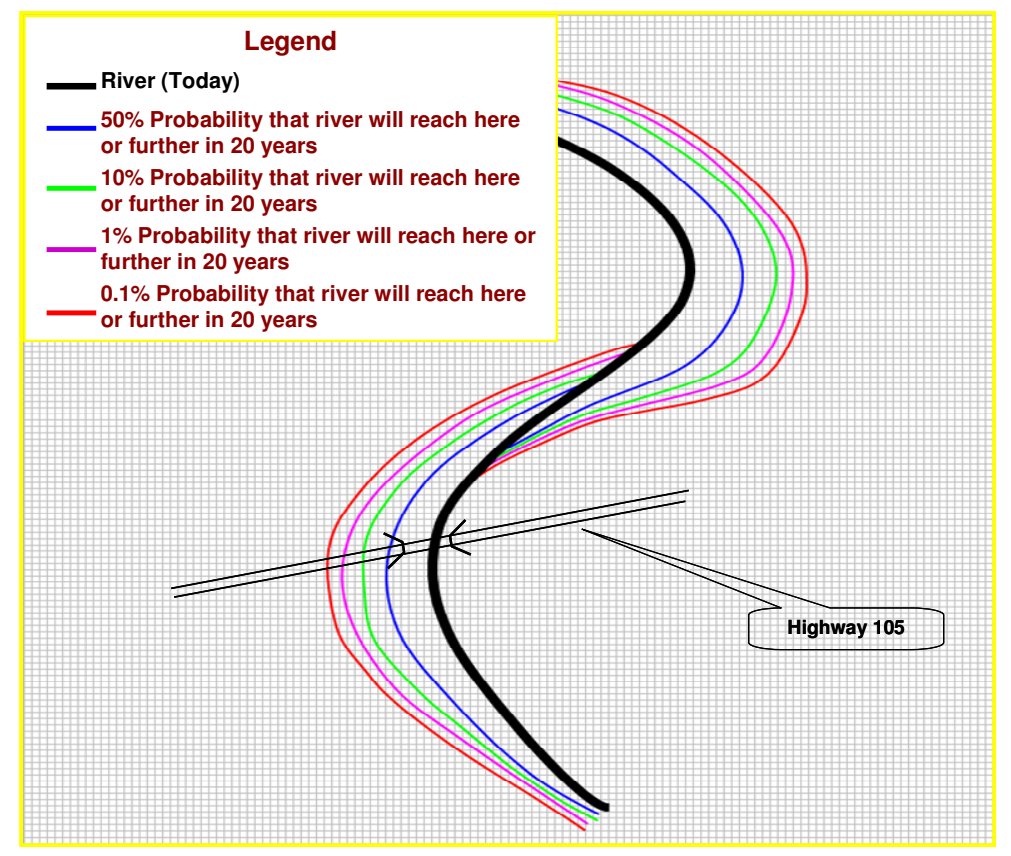

Fig.33 Conceptual presentation of the meandering risk for a river

in Fig. 31 were organized in a lognormal distribution, then a series of say 1000 equally likely future hydrographs were generated through random sampling of the hydrograph distribution over a chosen period of say 20 years, for each hydrograph the location of the river after the 20 year period was found, leading to a density of river locations within a grid. That density map was then transformed into a probability of exceedance map by simply counting how many times the river was located further than a certain point. This led to the plot shown conceptually on Fig. 33.

\section{THE NORMANDY CLIFFS CASE HISTORY (Briaud et al, 2007b)}

The erosion and associated retreat of cliffs is a natural process affecting coast lines all over the world. Many engineers and researchers have contributed to understanding this process including Emery and Kuhn (1982), Benumof and Griggs (1999), Henaf et al. (2002), and the wealth of information found in Mortimore and Duperret (2004). The following case history describes the process followed to explain the failure mechanism of the cliffs at the World War II historical site of Pointe $\mathrm{du}$ Hoc in Normandy, France and to suggest a remediation scheme.

\section{(1) History and observations}

On June 6, 1944, General Rudder and 200 American rangers assaulted the cliffs of Pointe du
Hoc to push back the Germans who had occupied France for several years. At the top of the cliffs, the Germans had built fortifications including an Observation Post (O.P.) near the edge of the cliff. Because of the retreat of the cliffs line, the O.P. has been closed to public visits because it could collapse down the cliff into the sea. Aerial photos indicate that some $10 \mathrm{~m}$. of erosion of the coast line has taken place between 1944 and 2006 at an average rate of $160 \mathrm{~mm} / \mathrm{yr}$ or $0.02 \mathrm{~mm} / \mathrm{hr}$. This prompted the study which is described next.

\section{(2) Rock erodibility}

Borings were drilled from the top of the cliffs. The stratigraphy obtained from the boring closest to the O.P. is shown on Fig. 34. It indicates that there is a soil cover about $8 \mathrm{~m}$ thick within which the O.P. is founded. Below the soil layer are interbedded layers of limestone and sandstone. In the soil layers, thin wall steel tube samples were pushed; in the rock, a core barrel was used to retrieve rock cores. Soil and rock samples were tested in the EFA. The erosion rates in the soil were relatively high (Category 2 and 3 ) and could not explain the observed cliff retreat rate of $0.02 \mathrm{~mm} / \mathrm{hr}$. The erosion rates obtained for the rock cores at $3.6 \mathrm{~m} / \mathrm{s}$ water velocity varied between 0.018 and $0.033 \mathrm{~mm} / \mathrm{hr}$. These rates are consistent with the observed rate of $0.02 \mathrm{~mm} / \mathrm{hr}$ but it would mean that the rock had been subjected to $3.6 \mathrm{~m} / \mathrm{s}$ of water velocity for the last 60 years. Obviously this is not the case as the rock is not subjected to water attack except during major winter storms; therefore rock substance erosion is not the explanation in this 


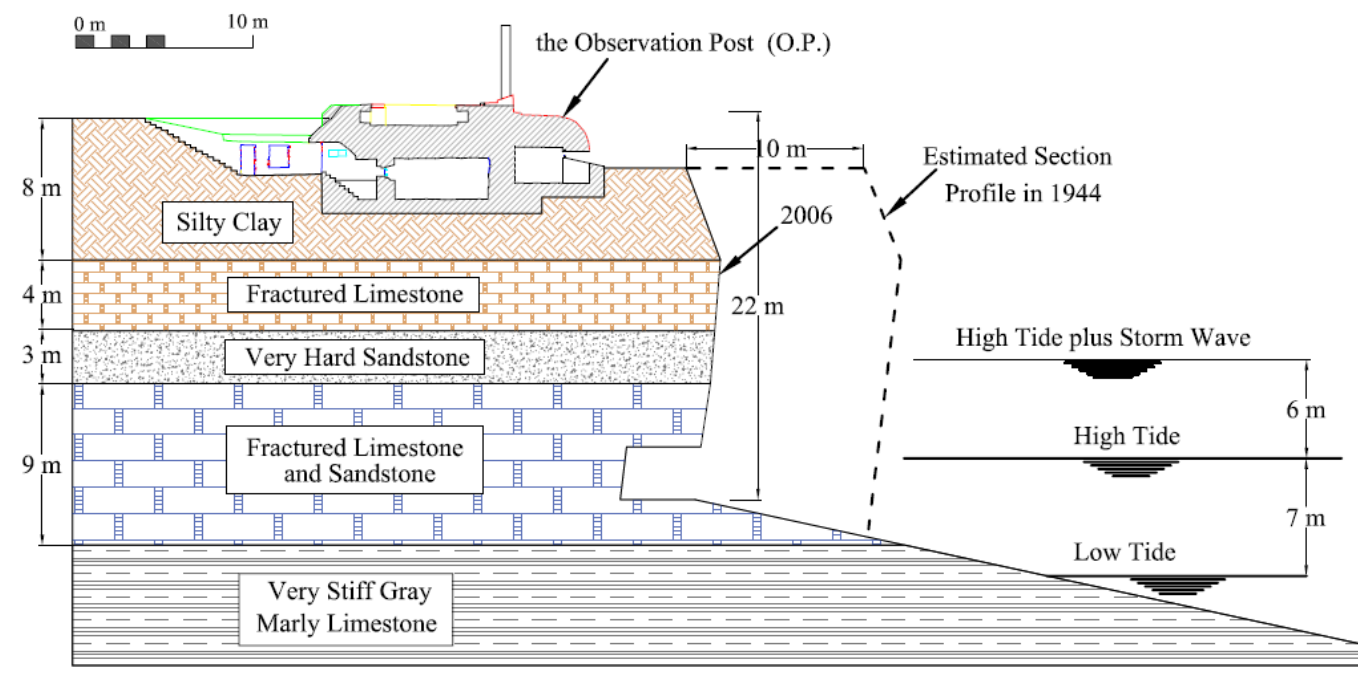

Fig.34 Sketch of the cliff cross section at Pointe du Hoc near the Observation Post

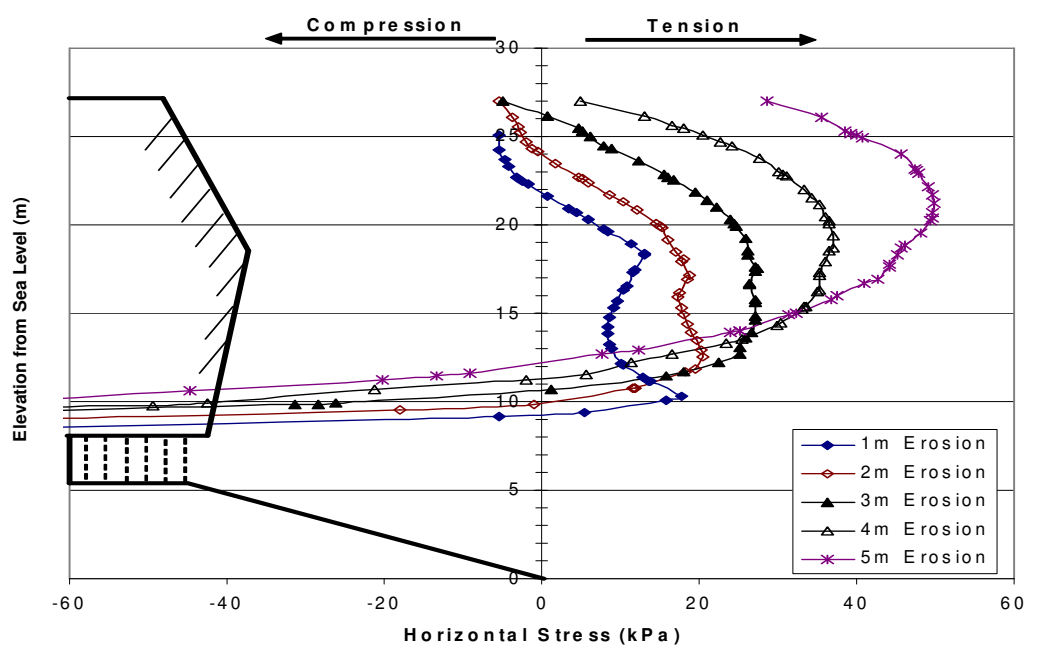

Fig.35 Stresses in the rock mass due to cliff over-hang (Finite Element Analysis)

case. Instead, rock mass erosion was the controlling factor as is often the case.

\section{(3) Water impact through waves}

The bottom of the cliff is attacked by waves especially during large winter storms. These waves can reach significant heights and have been recorded to reach $6 \mathrm{~m}$. These waves are superposed to the tides which can fluctuate by as much as $7 \mathrm{~m}$. If a storm occurs at high tide, the top of the large waves can reach half way up the cliff (Fig. 34).

\section{(4) Geometry of the obstacle}

The cliffs are vertical walls which are about $25 \mathrm{~m}$ high. Inspection of the bottom of the cliffs showed the presence of caverns some of which were $3 \mathrm{~m}$ high and $3 \mathrm{~m}$ deep on the West side of the Pointe.

\section{(5) Failure mechanism}

Observations at the bottom of the cliffs indicated that large masses of cliffs had collapsed and that the failure plane was vertical. The rock plates which were lying on the beach were about $4 \mathrm{~m}$ long and $1 \mathrm{~m}$ thick. Therefore it is postulated that the failure mechanism explaining the erosion retreat of the cliffs is the removal of the rock blocks by the waves at the bottom of the cliffs during large storms until the depth of the caverns becomes too large for the rock mass to sustain the weight of the overhang. This depth is likely to be about $4 \mathrm{~m}$ since the rock blocks lying on the beach are about $4 \mathrm{~m}$ long. Since the cliff line has lost $10 \mathrm{~m}$ in 60 years, such massive collapse would occur about every 25 years. The fresh water which seeps through the rock mass after heavy rains can create internal caverns in the limestone by dissolution. The fresh water seeps are also likely to remove soil from the joints between rock blocks and 

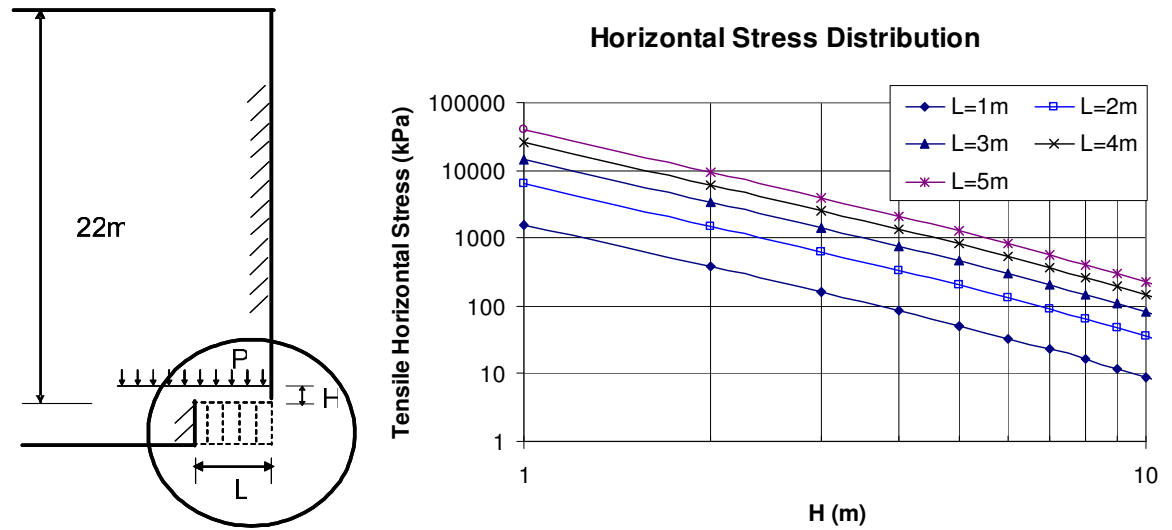

Fig.36 Maximum tensile stress in the rock beam for the cantilever analysis

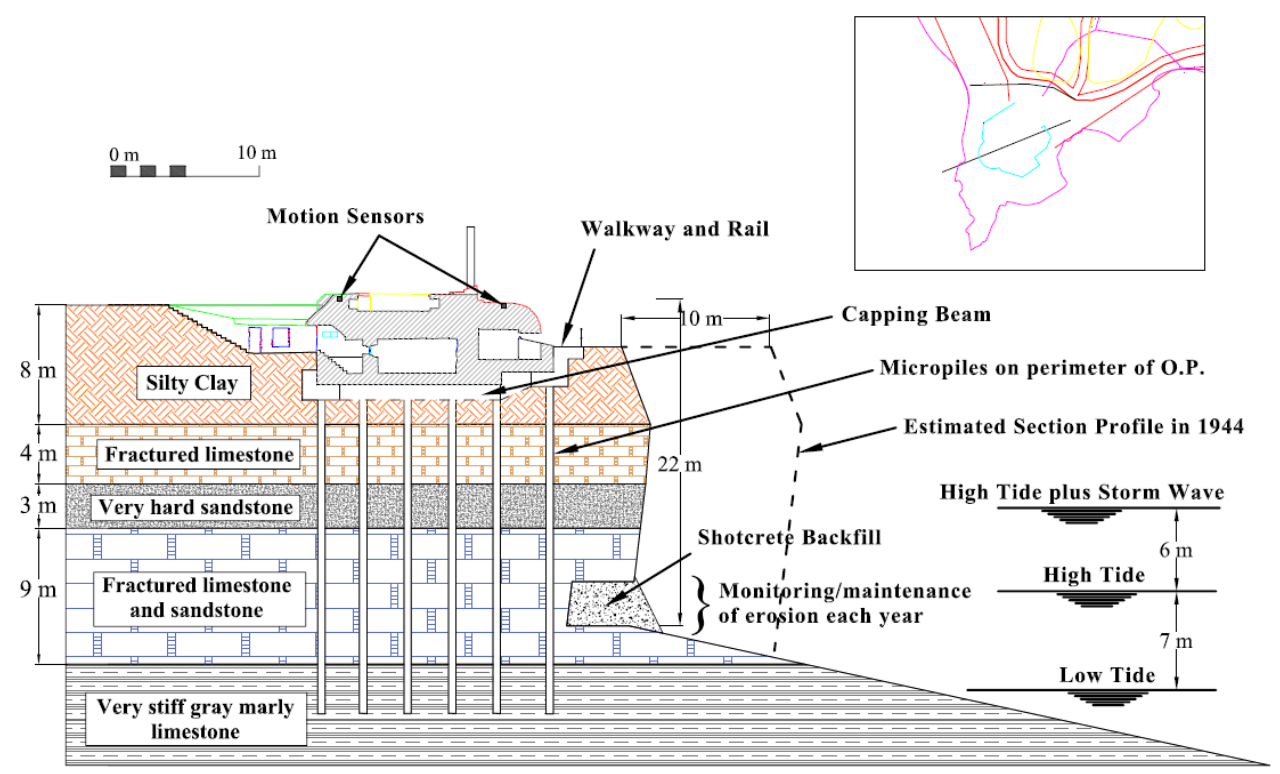

Fig.37 Proposed remediation for reopening the Observation Post at Pointe du Hoc

Table 3 Tensile strength $s_{t}$ of intact rock measured by the splitting strength test

\begin{tabular}{cccc}
\hline \multirow{2}{*}{ Sample } & $(\mathrm{MPa})$ & $\left(\mathrm{kN} / \mathrm{m}^{3}\right)$ & $(\%)$ \\
\cline { 2 - 4 } & $\mathrm{s}_{\mathrm{t}}$ & $\gamma_{\mathrm{t}}$ & $w_{c}$ \\
\hline Limestone & 3.36 & 24.90 & 3.12 \\
\hline Sandstone & 4.55 & 23.49 & 1.48 \\
\hline Marly Limestone & 4.52 & 24.53 & 3.83 \\
\hline
\end{tabular}

make them freer to move. Such seeps were found throughout the cliff face. In addition, the lateral stress relief due to the proximity of the cliff free boundary favors the opening and widening of rock joints. Then during major storms, the waves attack repeatedly the cliffs bottom and drag the loosened rock blocks out to sea upon their retreat from the beach. It was shown that the forces necessary to slide such rock blocks were well within the range of forces generated by the wave pressures (Briaud et al, 2007b).

Finite element simulations of the over-hanged cross section were carried out to find the maximum tensile stress in the rock mass if it was a continuum. Fig. 35 shows the results and indicates that the tensile stresses were at most equal to $50 \mathrm{kPa}$; this is very low compared to the tensile strength of the intact rock (Table 3) but could be comparable to the rock mass tensile strength. Indeed if the rock cliff overhang collapses when the caverns are $4 \mathrm{~m}$ deep, then according to Figure 35 the equivalent rock mass tensile strength is $40 \mathrm{kPa}$ or about $1 / 100$ of the intact rock tensile strength. If one assumes that a rock beam holds the roof of the cavern and is loaded by the weight of the cliff mass above it, a simple cantilever beam analysis can be conducted. Fig. 36 shows the results of such an analysis. In this case the stresses are reaching the tensile strength of the intact 


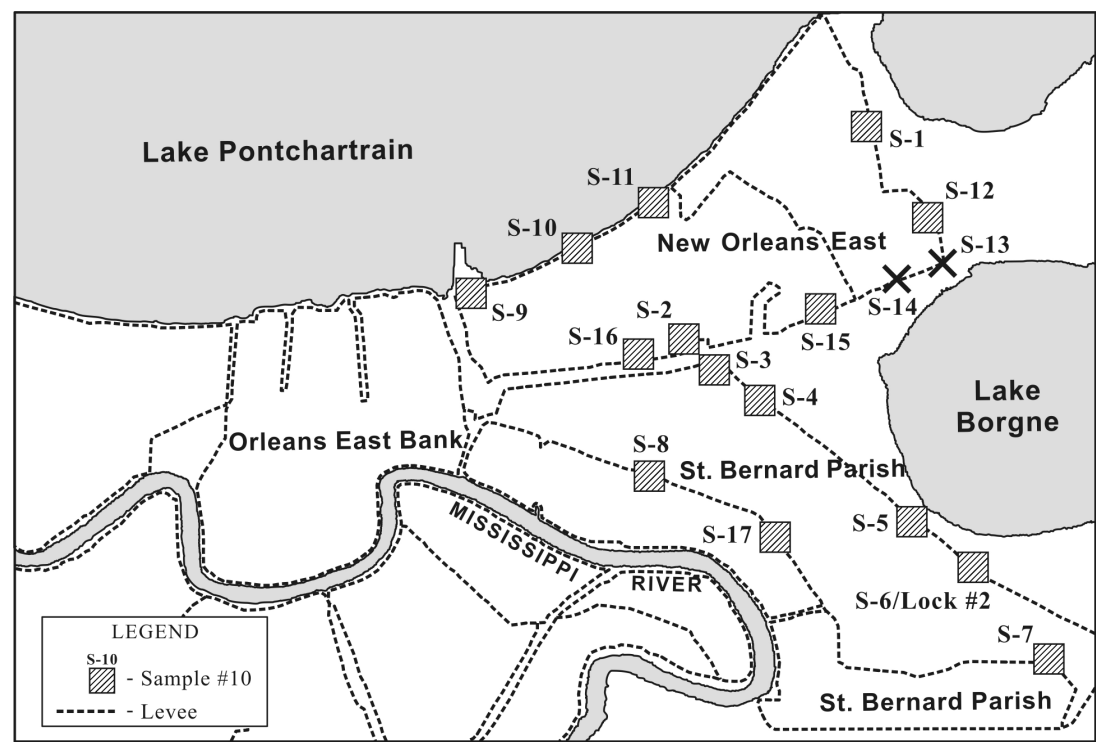

Fig.38 Location of shallow samples collected from the top of the levees

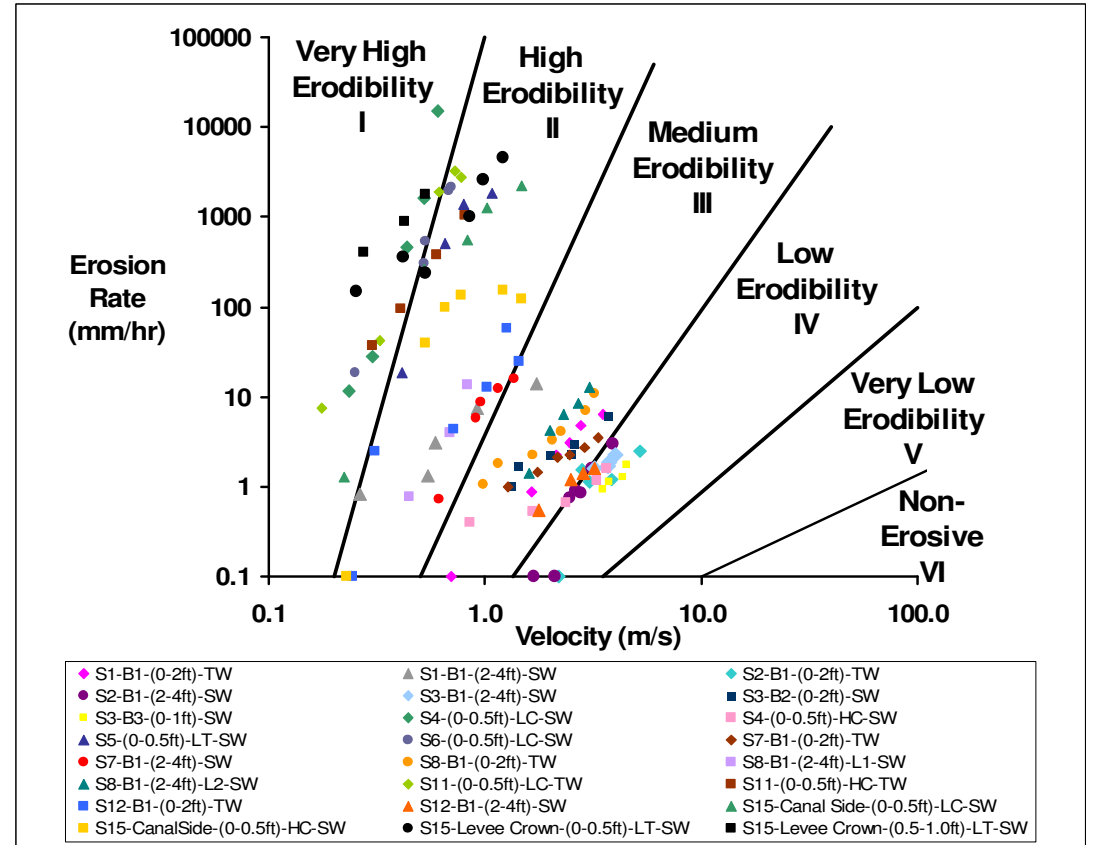

Fig.39 EFA test results in terms of velocity for some levee soils

rock (Table 3) which was measured by the splitting strength test (ASTM D-3967).

The recommended remediation steps are shown on Fig. 37 and consist of backfilling the caverns with grout under pressure to support their roof, to place the O.P. on micropiles, and to start a monitoring program to provide maintenance of the cliff base as necessary.

\section{THE NEW ORLEANS LEVEES CASE HITORY (Briaud, 2006b)}

On August 29, 2005, levee overtopping and associated erosion contributed significantly to the Katrina hurricane disaster in New Orleans where some places are $6 \mathrm{~m}$ below the top of the levees. This case history describes the process by which over topped levees erode and whether or not unprotected soils can resist overtopping erosion.

\section{(1) Soil erodibility}

Thin wall steel tube samples and bag samples were obtained from the top of the levees at shallow depth (0 to $1 \mathrm{~m}$ ). Shelby tube samples were collected from locations S1, S2, S3, S7, S8, S12 on Fig. 38. Bag samples were collected from locations S4, S5, S6, S11, S15 on Fig. 38. The bag samples were 


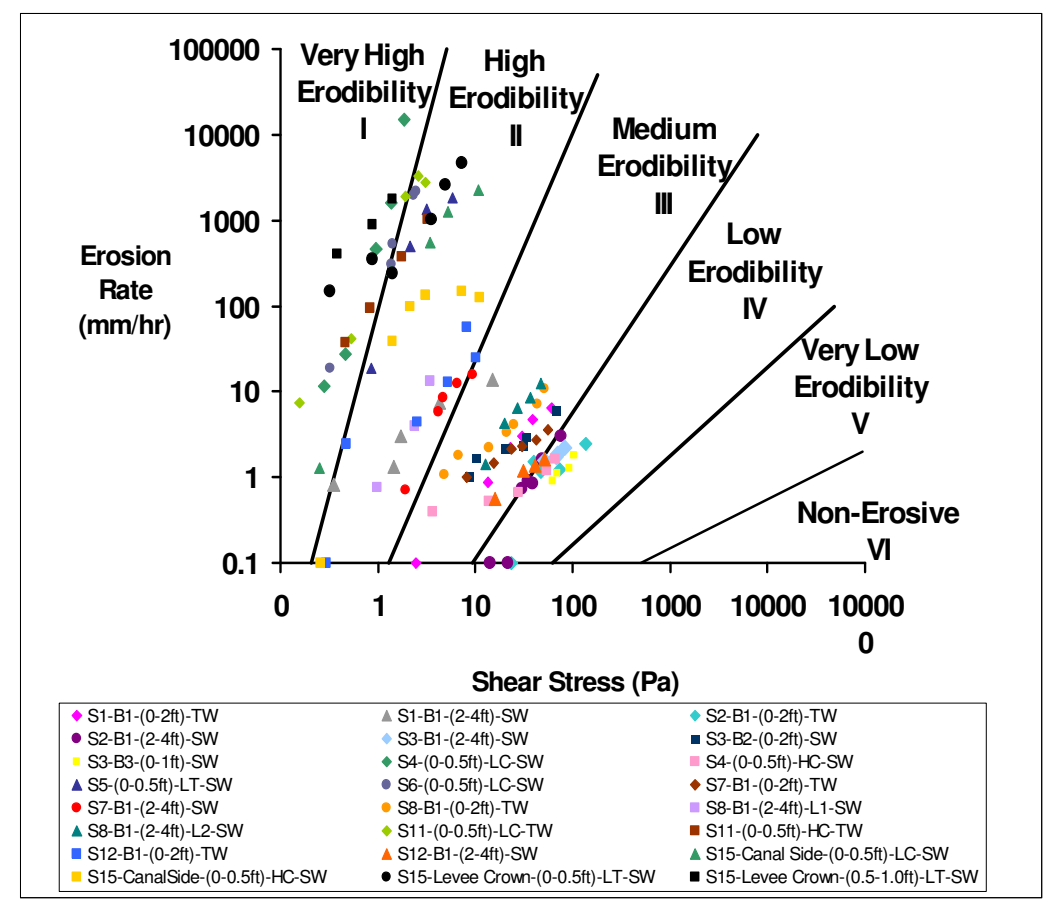

Fig.40 EFA test results in terms of shear stress for some levee soils
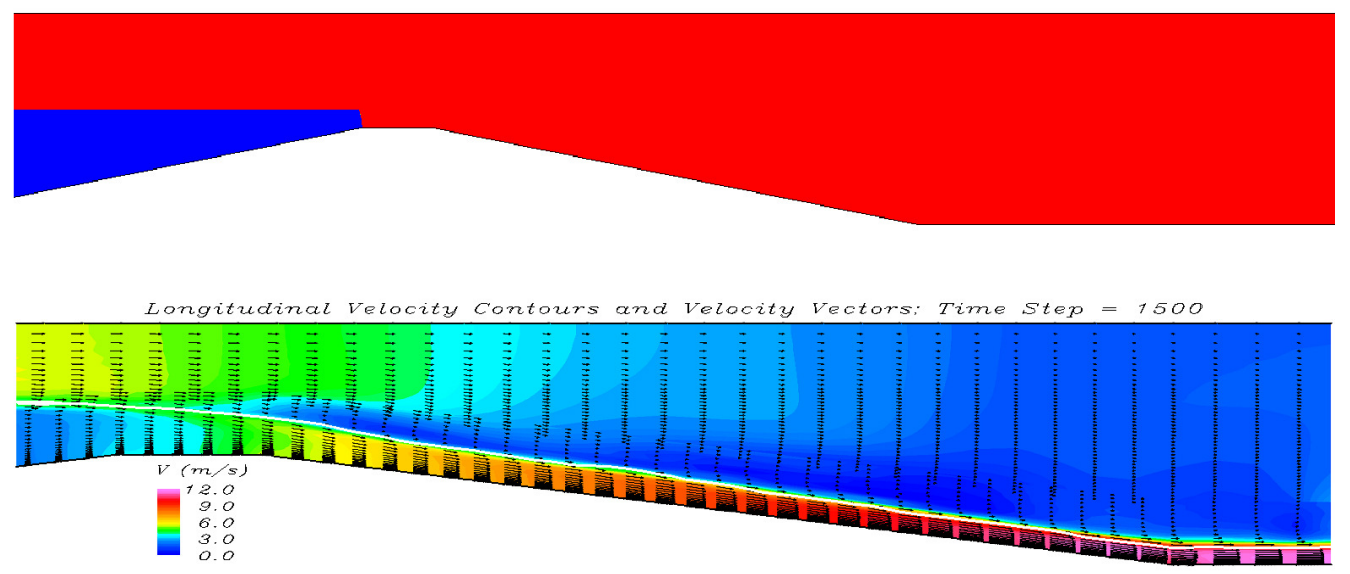

Fig.41 Distribution of velocities on the land side of a levee $2.39 \mathrm{~s}$ after overtopping

reconstituted in a Shelby tube by recompacting the soil at a low and at a high compaction effort (Briaud, 2006b). The soil type varied widely from loose uniform fine sand to high plasticity stiff clay. EFA tests were performed on the samples. Some of the samples were tested with simulated sea water (35000 ppm. salt concentration), some of the samples were tested with tap water (500 ppm). The results of all the tests are shown on Fig. 39 and 40.

One of the first observations coming from the summary erosion chart on Fig. 39 is that the erodibility of the soils obtained from the New Orleans levees varies widely all the way from very high erodibility (Category 1) to low erodibility (Category 4). This explains in part why some of the overtopped levees failed while other overtopped levees did not. It was also found that resistance to erosion increases with compaction effort but that the effect is more significant for some soils (higher fine content) than for others (lower fine content). The salinity of the water was also found to have an influence although no clear trend was discerned. Previous findings on controlled samples of porcelain clay indicated that an increase in salinity of the water flowing over the soil from tap water to sea water leads to a higher critical velocity and a lower erosion rate for the same soil (Cao et al., 2002).

\section{(2) Water velocity}

Hurricanes are large rotating masses of moisture which can be $400 \mathrm{~km}$ in diameter. They travel relatively slowly at speeds of about $40 \mathrm{~km} / \mathrm{hr}$. Therefore a hurricane takes about $10 \mathrm{hr}$ to go over a levee or a bridge, however the worst part of the storm 


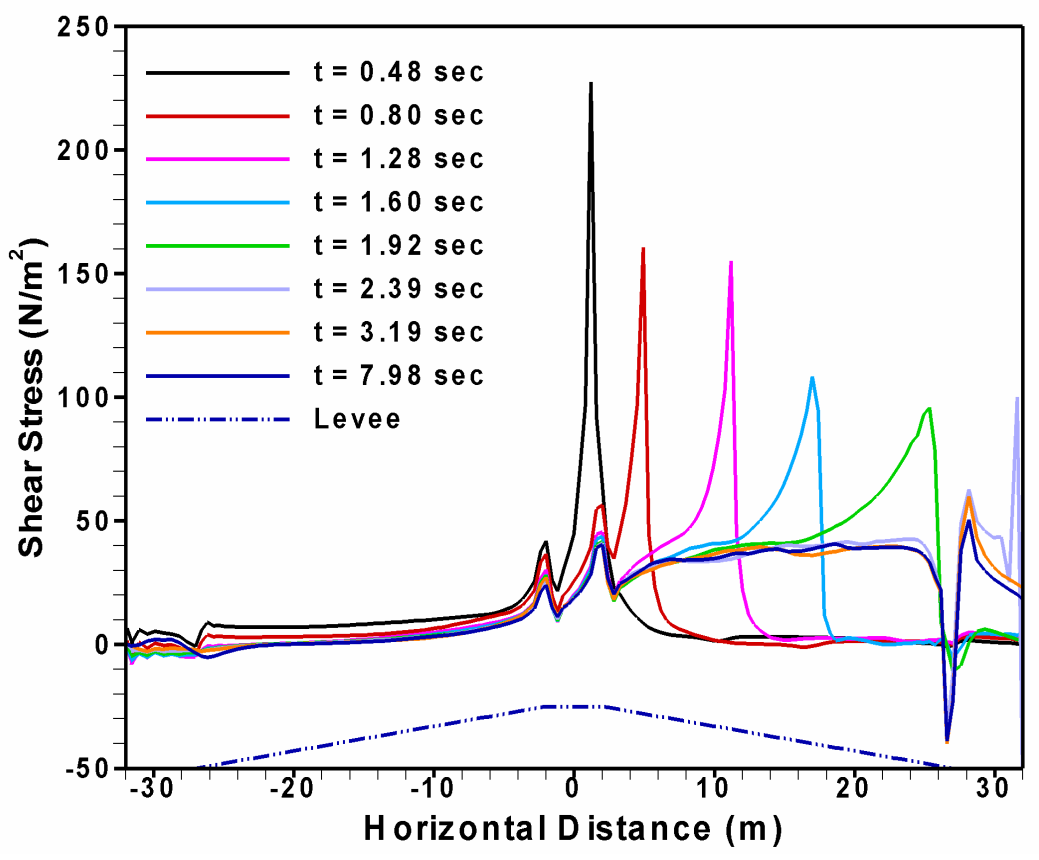

Fig.42 Shear stress at the water soil interface on the land side of a levee during overtopping

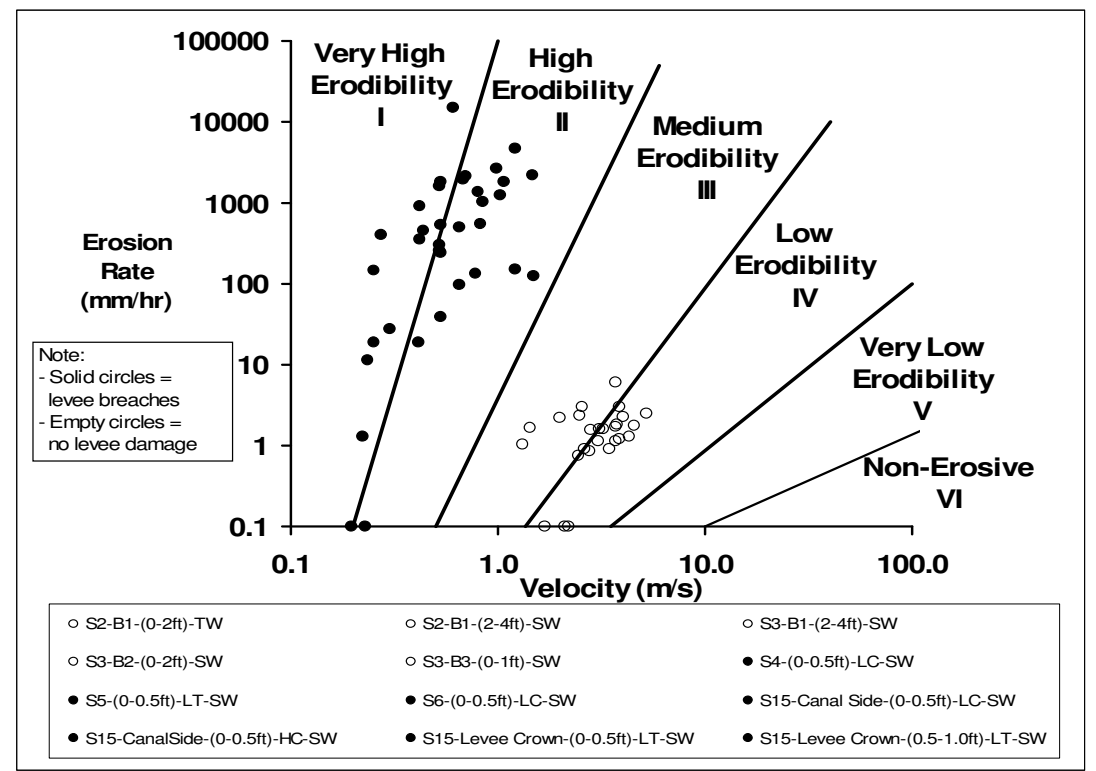

Fig.43 EFA test results for the soils of levees which failed and did not fail by overtopping erosion

is only a fraction of that time. The friction generated by the wind at the air-water interface drags the water into a storm surge which can reach several meters above the mean sea level and kilometers in length. The surge associated with Katrina was about $8.5 \mathrm{~m}$ at Bay St. Louis, $4.6 \mathrm{~m}$ at Lake Borgne, and $3 \mathrm{~m}$ at Lake Pontchartrain. The storm surge was high enough to overtop some of the levees. In order to obtain the velocity of the water flowing down the land side of the levee and the corresponding interface shear stress, numerical simulations were conducted. The simulated levee was $5 \mathrm{~m}$ high with 5 to 1 slopes on both sides. The initial conditions were set for a water height of $1 \mathrm{~m}$ above the top of the levee and an initial horizontal water velocity of $3 \mathrm{~m} / \mathrm{s}$. As can be seen from Fig. 41, the water velocity at the bottom of the slope on the land side reached $12 \mathrm{~m} / \mathrm{s}$. The shear stress is also very high as seen on Fig. 41 with a steady state value (7.98 s. on Fig. 42) of $35 \mathrm{kPa}$.

\section{(3) Geometry of the obstacle}

Most levees around New Orleans are between 3 and $6 \mathrm{~m}$ high. They have two main shapes. The first one consists of a flat top which is some $4 \mathrm{~m}$ wide with side slopes at about 5 horizontal to 1 vertical. Because the width of such a levee configuration 


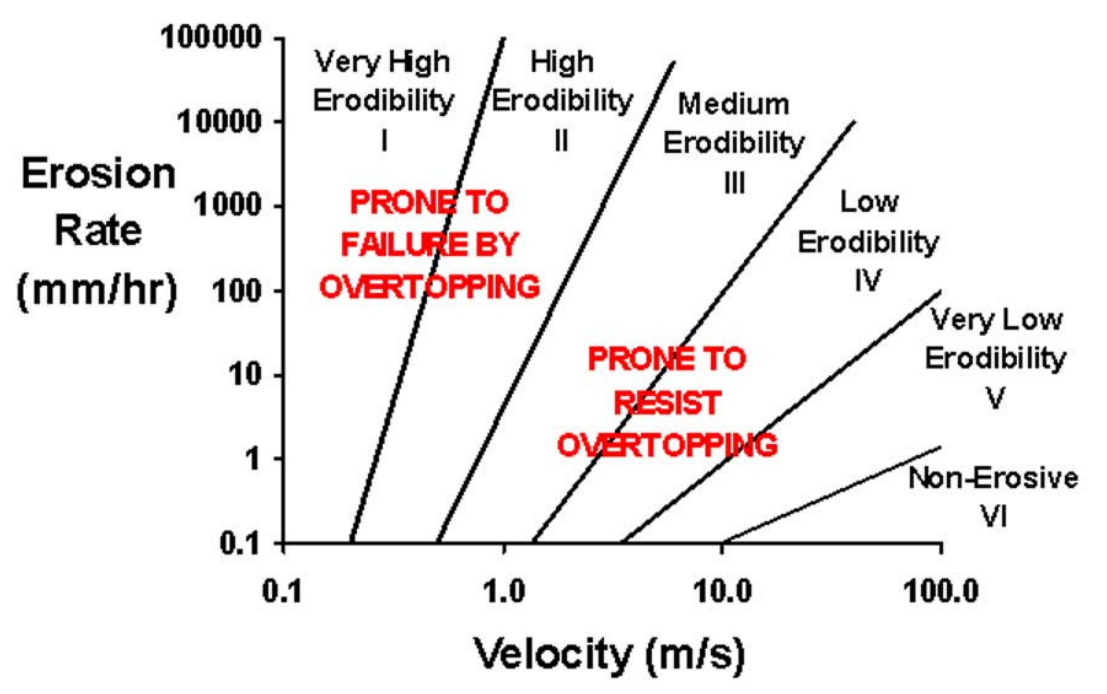

Fig.44 Recommended levee overtopping chart for a few hours of overtopping at most

takes a lot of space, the second shape consists of the same shape as the first one at a reduce scale with a vertical wall extending on top of the levee. The problem addressed here is limited to the first shape.

\section{(4) Predicting levee overtopping erosion}

There was overwhelming evidence that the water overtopped the levees in many places; such evidence consisted mostly of ships being trapped on top of the levees when the water receded but also of debris stuck in trees at levels higher than the top of the levees. Some levees resisted the overtopping well, some levees were completely eroded. On Fig. 43, the erodibility functions for the samples taken from levees that were overtopped and resisted well are plotted as open circles while the solid dots are for the samples of levees that were completely eroded. As can be seen, the eroded levees were made of soils in the erodibility categories 1 and 2 while the levees which resisted well were made of soils in the erodibility categories 3 and 4 . This led to the levee overtopping chart shown in Fig. 44.

\section{CONCLUSIONS}

Scour and erosion is a large field of civil engineering which includes bridge scour, cliff erosion, levee erosion, meander migration, piping in dams, construction sites surface erosion, highway embankment surface erosion, beach erosion, erosion of spillway landings. The case histories described in this lecture cover some of those topics and give examples of approaches available to study, predict, and design against erosion. They also show the broad applicability of the Erosion Function Apparatus. Geotechnical engineers need to get involved as the development of the soil and rock side of the field both in terms of practice and research is seriously lagging behind the hydraulic side. The power point slides for the lecture including many photos of the case histories are available at http://ceprofs.tamu.edu/briaud/ under "Lectures" and the video (DVD) of the lecture is available from the author free of charge.

ACKNOWLEDGMENT: Many students, many university colleagues, many practitioner colleagues have contributed to making this lecture possible. One of the great pleasures in preparing this lecture was to feel the power of team work. Thank you all for being part of the $9^{\text {th }}$ Ralph B. Peck Lecture team: Hamn-Ching Chen (Texas A\&M), Kuang-An Chang (Texas A\&M), Anand Govindasamy (Texas A\&M), Namgyu Park (Texas A\&M), Po Yeh (Texas A\&M), Jennifer Nicks (Texas A\&M), Ok-Youn Yu (Texas A\&M), Remon Abdelmalak (Texas A\&M), Xingnian Chen (Texas A\&M), Rick Ellman (Mueser Rutledge), Bea Hunt (Hardesty \& Hanover), Stan Davis (Maryland SHA), Sterling Jones (FHWA), Rune Storesund (UC Berkeley), Ray Seed (UC Berkeley), Bob Bea (UC Berkeley), Tom Dahl (TxDOT), Bob Warden (Texas A\&M), Mark Everett (Texas A\&M), Phil Buchanan (Buchanan Soil Mechanics).

\section{REFERENCES}

1) Annandale, G. W. : Erodibility, Journal of Hydraulic Research, vol. 33, No. 4, pp. 471-494, 1995.

2) Annandale, G.W.: Prediction of scour at bridge pier foundations founded on rock and other earth materials, Transportation Research Record No. 1696, pp. 67-70 2000.

3) Arulanandan, K., Sargunam, A., Loganathan, P., and Krone, R. B. : Application of chemical and electrical parameters to prediction of erodibility, Soil erosion: Causes and mechanisms; prevention and control, Special Rep. 135, Highway Research Board, Washington, D.C., pp. 42-51, 
1973.

4) Benumof, B. T. \& Griggs G. B. : The Dependance of Sea-cliff Erosion Rates on Cliff Material Properties and Physical Processes: San Diego County, California, Journal of Shore and Beach, V. 67, No. 4, pp. 29-41, 1999.

5) Bolduc L.C., Gardoni P., Briaud J.-L. : Probability of Exceedance Estimates for Scour Depth Around Bridge Piers, Journal of Geotechnical and Geoenvironmental Engineering, Vol. 134, No. 2, pp. 175-184, 2008.

6) Bollaert, E. : Transient Water Pressures in Joints and Formation of Rock Scour due to High-Velocity Jet Impact, Communication No. 13. Laboratory of Hydraulic Constructions, Ecole Polytechnique Federale de Lausanne, Switzerland, 2002.

7) Brandimarte L., Montanari A., Briaud J.-L., D’Odorico P. : Stochastic Flow Analysis for Predicting Scour of Cohesive Soils, Journal of Hydraulic Engineering, Vol. 132, No. 5, pp. 493-500, 2006.

8) Briaud J.-L. : Bridge Scour, Geotechnical News edited by BiTech Publishers Ltd, Vol. 24, No.3, September, 2006a

9) Briaud J.-L. : Erosion Tests on New Orleans Levee Samples, Internal Report, Zachry Dpt. of Civil Engineering, Texas A\&M University, College Station, pp107, 2006b.

10) Briaud J.-L., Abdelmalak R., Smith B. : Pointe du Hoc stabilization study: geotechnical report on geotechnical testing, failure analysis, and remedial measures, Research report to the American Battle Monuments Commission, $2007 \mathrm{~b}$.

11) Briaud J.-L., Brandimarte L., Wang J., D'Odorico P. : Probability of Scour Depth Exceedance due to Hydrologic Uncertainty, Georisk Journal for Assessment and Management of Risk for Engineered Systems and Geohazards, Vol.1, No.2, pp. 77-88, 2007.

12) Briaud J.-L., Chen H.-C., Chang K.-A., Chung Y.-A., Park N., Wang W., Yeh P.-H. : Establish guidance for soil properties-based prediction of meander migration rate, Report FHWA/TX-07/0-4378-1, 2007a.

13) Briaud J.-L., Chen H.-C., Li Y., Nurtjahyo P., Wang J. : The SRICOS-EFA Method for Complex Piers in Fine Grained Soils, Journal of Geotechnical and Geoenvironmental Engineering, Vol 130, No. 11, p1180-1191, 2004a.

14) Briaud J.-L., Chen H.-C., Li Y., Nurtjahyo P., Wang J. : The SRICOS-EFA Method for Contraction Scour in Fine Grained Soils, Journal of Geotechnical and Geoenvironmental Engineering, Vol. 131, No.10, pp.1283-1294, 2005.

15) Briaud J.-L., Chen H.-C., Nurtjahyo P., Wang J. : Pier and Contraction Scour in Cohesive Soils, NCHRP Report 516, Transportation Research Board, 2004b.

16) Briaud J.-L., Chen, H. C. Kwak K., Han S-W., Ting F. : Multiflood and Multilayer Method for Scour Rate Prediction at Bridge Piers, Journal of Geotechnical and Geoenvironmental Engineering, Vol.127, No. 2, pp.114-125, 2001b.

17) Briaud J.-L., Ting F. C. K., Chen H. C., Gudavalli R., Perugu S., Wei G. : SRICOS: Prediction of Scour Rate in Cohesive Soils at Bridge Piers, Journal of Geotechnical and Geoenvironmental Engineering, Vol. 125, No.4, pp. 237-246, 1999.

18) Briaud J.-L., Ting F., Chen H.C., Cao Y., Han S.-W., Kwak K. : Erosion Function Apparatus for Scour Rate Predictions, Journal of Geotechnical and Geoenvironmental Engineering, Vol. 127, No.2, pp. 105-113, 2001a.

19) Briaud J.-L., Tucker L.M. : Measured and Predicted Axial Response of 98 Piles, Journal of Geotechnical Engineering, Vol. 114, No. 9, 1988.

20) Brice, J. C. : Evolution of Meander Loops," Geological
Society of America Bulletin, Vol. 85, pp. 581-586, 1974.

21) Brunner, G.W. : HEC-RAS River Analysis System Hydraulic Reference Manual, Ver. 3.1, Report No. CPD-69, U.S. Army Corps of Engineers, 2002.

22) Cao Y., Wang J. , Briaud J.L., Chen H.C., Li Y., Nurtjahyo P. : EFA Tests and the influence of Various Factors on the Erodibility of Cohesive Soils, Proc. of the $1^{\text {st }}$ Int. Conf. on Scour of Foundations, 2002.

23) Chapuis, R. P., and Gatien, T. : An improved rotating cylinder technique for quantitative measurements of the scour resistance of clays. Can. Geotech. J., Vol. 23, pp. 83-87, 1986.

24) Chen H.-C., Chen M. : Chimera RANS Simulation of a Berthing DDG-51 Ship in Translational and Rotational Motions, Int. Journal of Offshore and Polar Engineering, Vol. 8, No. 3, 1998.

25) Chen H.-C., Patel V.C. : Near-Wall Turbulence Models for Complex Flows Including Separation, AIAA Journal, Vol. 26, No. 6, pp641-648, 1988.

26) Chen H.-C., Patel V.C., Ju S. : Solution of Reynolds-Averaged Navier Stokes Equations for Three-Dimensional Incompressible Flows, Journal of Computational Physics, Vol. 88, No. 2, pp305-336, 1990.

27) Chen, H.C. : Assessment of a Reynolds Stress Closure Model for Appendage-Hull Junction Flows, ASME Journal of Fluids Engineering, Vol. 117, No. 4, pp. 557-563, 1995.

28) Chen, H.C. : Numerical Simulation of Scour Around Complex Piers in Cohesive Soil, Proc. of 1st Int. Conf. on Scour of Foundations, pp. 14-33, 2002.

29) Chen, H.C., Jang, Y.J. and Han, J.C. : Assessment of a Near-Wall Second-Moment Closure for Rotating Multiple-Pass Cooling Channels, AIAA Journal of Thermophysics and Heat Transfer, Vol. 14, No. 2, pp. 201-209, 2000.

30) Chow V.T., Maidment, D.R., and Mays, L.W. : Applied Hydrology, pp. 375-378, 1988.

31) Croad, R.N. : Physics of Erosion of Cohesive Soils, PhD Thesis, Department of Civil Engineering, University of Auckland, New Zealand, 1981.

32) Davis S.M. : Scour evaluation study for the replacement of the Woodrow Wilson Memorial Bridge, Maryland State Highway Administration, Baltimore, USA, 2001.

33) Emery, K. O. \& Kuhn, G. G. : Sea cliffs: their processes, profiles, and classification, Geological Society of American Bulletin, No.93, pp. 644-654, 1982.

34) Hanson, G. J. : Development of a jet index to characterize erosion resistance of soils in earthen spillways. Trans. ASAE, Vol. 34, No.5, pp.2015-2020, 1991.

35) Hénaff A., Lageat Y., Costa S. and Plessis E. : Le recul des falaises crayeuses du Pays de Caux : détermination des processus d'érosion et quantification des rythmes d'évolution, Géomorphologie : relief, processus, environnement, No.2, pp. 107-118, 2002.

36) Hickin, E. J., and Nanson, G. C. : Lateral Migration Rates of River Bends, American Society of Civil Engineers, Journal of Hydraulic Engineering, Vol. 110, pp. 1557-1567, 1984.

37) Hjulström, F. : The morphological activity of rivers as illustrated by river Fyris, Bulletin of the Geological Institute Uppsala No.25, Chapter 3, p. 221, 1935.

38) Hoffmans, G.J.C.M. and Verheij, H.J. : Scour Manual, Balkema, Rotterdam, 1997.

39) Hofland, B., Battjes, J.A., and Booij, R. : Measurement of fluctuating pressures on coarse bed material, Journal of Hydraulic Engineering, Vol. 131, No. 9, pp.770-781, 2005.

40) Hooke, J. M. : Changes in River Meanders : A Review of Techniques and Results of Analysis, Progress in Physical Geography, Vol. 8, pp. 473-508, 1984. 
41) Hunt B.E. : personal communication, STV Inc., New York City, 2001.

42) Kirsten, H.A.D., Moore, J.S., Kirsten, L.H., and Temple, D.M. : Erodibility Criterion for Auxiliary Spillways of Dams, ASAE International Meeting, Phoenix, Arizona Paper No. 962099, 1996.

43) Kwak K., Briaud J.-L., Cao Y., Chung M.-K., Hunt B., Davis S. : Pier Scour at Woodrow Wilson Bridge and SRICOS Method, Proc. of the 1st Int. Conf. on Scour of Foundations, 2002.

44) Kwak K., Briaud J.-L., Chen H.-C. : SRICOS: Computer Program for Bridge Pier Scour, Proc. of the 15th Int. Conf. on Soil Mechanics and Geotechnical Engineering, Vol. 3, pp. 2235-2238, 2001.

45) Manso, P.F. : The influence of Pool Geometry and Induced Flow Patterns in Rock Scour by High-Velocity Plunging Jets, PhD Thesis, Laboratory of Hydraulic Constructions, Ecole Polytechnique Federale de Lausanne, Switzerland, 2006.

46) Moody L.F. : Friction Factors for Pipe Flow", Transaction of the American Society of Civil Engineers, Vol. 66, 1944.

47) Mortimore, R. N. \& Duperret, A. (eds) : Coastal Chalk Cliff Instability, Geological Society, London, Engineering Geology Special Publication, 20, 2004.

48) Nurtjahyo P.Y. : Chimera RANS Simulations of Pier Scour and Contraction Scour in Cohesive Soils, PhD. Dissertation, Zachry Dpt of Civil Engineering, Texas A\&M University, USA, 2003.

49) Park N. : A prediction of meander migration based on large-scale flume tests in clay", PhD Dissertation, Zachry Dpt. of Civil Engineering, Texas A\&M University, USA, 2007.

50) Raudkivi, A.J. : Loose Boundary Hydraulics, Balkema, 1998.

51) Richardson E.V., Davis S.M. : Evaluating Scour at Bridges,
Publication No. FWHA-IP-90-017, Hydraulic Engineering Circular No.18, Federal Highway Administration, US Department of Transportation, 2001.

52) Salim M., Jones J. S. : Scour Around Exposed Pile Foundations, ASCE Compendium of Conference Scour Papers (1991 to 1998), pp. 104-119, 1998.

53) Sherard, J. L. : Hydraulic fracturing in embankment dams, Proc., Symp. on Seepage and Leakage from Dams and Impoundments. R. L. Volpe and W. E. Kelly, eds., NewYork, pp.115-141, 1985.

54) Shields, A. : Anwendung der Aehnlichkeitsmechanik und der Turbulenzforschung auf die Geschiebebewegung, Doktor-Ingenieurs dissertation, Technischen Hochschule, Berlin (in German), 1936.

55) Temple, D.M. and Moore, J.S. : Headcut Advance Prediction for Earth Spillways, Proc. of ASAE International Winter Meeting, Atlanta, Paper No. 942540, 1994.

56) Van Schalkwyk, A., Jordaan, J.M., and Dooge, N. : The Erodibility of Different Rock Formations, Water Research Commission, Report No. 302/1/95, Pretoria, South Africa, 1995.

57) W. de Moor J.J., van Balen R.T., Kasse C. : Simulating meander evolution of the Geul River (the Netherlands) using a topographic steering model, Earth Surface Processes and Landforms, Vol. 32, No. 7, pp.1077-1093, 2007.

58) Wan C.F., Fell R. : Investigation of Rate of Erosion of Soils in Embankment Dams, J. Geotech. and Geoenvir. Engrg., Vol. 130, No. 4, pp. 373-380, 2004.

59) Wang W. : A hydrograph-based prediction of meander migration, $\mathrm{PhD}$ Dissertation, Zachry Dpt. of Civil Engineering, Texas A\&M University, USA, 2006.

60) Yeh P.-H. : Physical models of meander channel migration, PhD Dissertation, Zachry Dpt. of Civil Engineering, Texas A\&M University, USA, 2008. 